\title{
Pre-service Secondary Mathematics Teachers' Metacognitive Awareness and Metacognitive Behaviours in Problem Solving Processes
}

\author{
Fatih Baş \\ Faculty of Education, Erzincan University, Turkey
}

Copyright $(2016$ by authors, all rights reserved. Authors agree that this article remains permanently open access under the terms of the Creative Commons Attribution License 4.0 International License

\begin{abstract}
This study aims to observe the pre-service secondary mathematics teachers' metacognitive awareness in terms of the variables gender and class level and determine their metacognitive behaviours which showed in the non-routine problems. A partially mixed sequential dominant status design was carried out with a total of 287 participants. The data of the qualitative part was collected with the Metacognitive Awareness Inventory and analysed descriptively and two-way ANOVA tests were conducted. The data of the quantitative part were collected with a non-routine problem within the scope of Multi-Method Interview and analysed descriptively. The findings showed that the levels of the pre-service secondary mathematics teachers' metacognitive awareness were medium or high and the levels are not different in terms of the variables of gender and class level. In addition, the participants showed metacognitive behaviours in the evaluation the most group and in the awareness group the least. Lastly, though the number of metacognitive behaviours showed by the fourth class pre-service teachers were higher than the other classes, there is not any difference in the order of their metacognitive behaviours in the class level.
\end{abstract}

Keywords Metacognition, Metacognitive Awareness, Metacognitive Behaviour Processes During Problem Solving Process

\section{Introduction}

A problem is accepted as a case containing open-ended questions, and taking the attention of an individual which the individual does not have the necessary algorithm and methodical knowledge to answer the questions [56]. Schoenfeld [6] explained this concept as a thing waiting to be answered in mathematics and a confusing question which cannot be solved easily. Problem-solving is a process of thinking which a person is trying to receive new information until s/he overcomes the stress caused by the problem and to search a reason which is suitable to the problem situation using his/her mathematical knowledge [19]. This process contributes to the mathematical skills of the students by using these skills in daily life [48] and it is emphasised in the mathematics education institutions [42-45] and curricula [55].

In order to reach the aimed achievement in the problem solving, it is necessary to raise individuals having sufficient cognitive learning and problem-solving skills [54]. While the mentioned cognitive learning is relevant to concepts of the problem structure and the operations during the solving, problem-solving skills are relevant to the functions enabling executing and using the cognitive competence correctly in the solving process. Though cognitive competence may vary according to the problems, the skills have more stable structures.

To gain and develop the problem-solving skills, it is important to observe and determine the problem-solving process and basic variables stated in the process in detail. This process was dealt with a four-stage structure as follows by Polya[25]; understanding the problem, making a plan, implementing the plan and evaluating the results. This structure which has a significant role in defining the problem-solving process also gave way to much research on this topic and contributed to creating new structures (i.e.; reading, analysis, exploration, planning/implementation, and verification as in [5]). Nevertheless, Polya [25] describing this structure, stated that the person answering the problem may give new directions to the process with evaluations during the problem-solving process. As stated in Figure 1, this variability was explained in mutual transitions between stages by Fernandez, Hadaway and Wilson[36].

The most remarkable point in the figure is that the mutual transitions between the stages of the problem-solving process are connected with the executive processes giving directions to these stages. Because it is not relevant to deal 
the problem-solving process with only the cognitive side [29]. In addition to the cognitive knowledge, some skills such as sufficient level of awareness related to this knowledge [31] and control concerning with the solving process, planning, monitoring and evaluation are also required $[13,29,31,47]$. The awareness and skills in the literature are considered within the scope of metacognition concept. Metacognition is defined as individuals' knowledge about their cognitive behaviours or arranging these behaviours through the learning process [8,32]. This concept contains two sides: knowledge-beliefs related to the case of cognition and arranging-monitoring of the cognitive behaviours which are connected with each other though they are different [31]. While cognition contains the behaviours being occurred, metacognition requires monitoring the previous behaviours, planning and choosing the things to do [18]. There is a close relation between these features attributed to metacognition and problem solving $[6,18,20,21,49,50$.$] .$

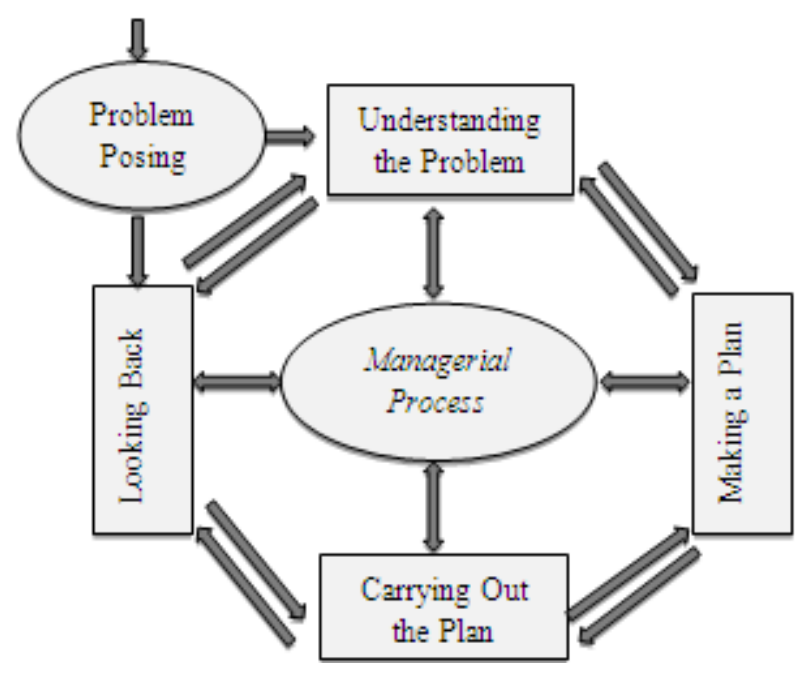

Figure 1. Problem solving process model which provided by Fernandez, Hadaway and Wilson[36]

In other words, the problem-solving management can be defined as a product of a complex interplay between cognition and metacognition [9]. On the basis of difficulties which students encountered in the problem-solving process is their disarranging the cognitive processes regularly [4]. Students who have this skill can have the ability to control and monitor process related to the problems, interrogate logically and make placements $[9,28,30]$. Much research showed that the students who often demonstrated metacognitive behaviours are mainly much more successful in mathematics [24,57], very active in the problem-solving process $[11,52]$ and also better in the problem solving $[9,11,27,29,53]$.

The development of the metacognitive skills continues developing during their age progress in parallel to the intelligence developments of students who learn more about strategies and topics, this progress is a long-term development process rather than an automatic process [9].
Thus, metacognitive development is both the result of the cognitive development and a function ensuring the cognitive development [9]. In spite of the benefits mentioned another situation in the literature is the existing limits of students' using the metacognitive behaviours both in the problem-solving processes [9] and in-class behaviours [39]. Although the common use of the metacognitive behaviours does not always assure the problem-solving achievement [33], the behaviours which enable the cognitive and metacognitive developments should also be included to increase the successes of problem solving [1].

The training on metacognitive behaviours may have increase the achievement of students in mathematics [51,58] more specifically in their mathematical problem-solving achievement $[1,3,14,23,37,59,60]$. Another significant point here is not only to give the metacognitive instruction to the students only at the end of the process but also in the whole process [17]. This can only be achieved with an effective planning. Teachers should have metacognitive skills and use these skills at a sufficient rate [39]. However, there is little research on this issue and it was seen that teachers have limited metacognitive skills and have very little knowledge of using these skills in the teaching process $[12,40]$. In addition, teachers, compared with the pre-service teachers, have both more metacognitive knowledge and metacognitive regulation [46]. When the importance of the pre-service education process for teachers was considered, the necessity of handling their metacognitive developments in this process in detail gains importance.

Considering in this context, the relevant research mainly focused on the pre- service teachers' behaviours on a certain problem statement $[10,11,53]$ and metacognitive awareness with a qualitative approach [46]. Yet, it is crucial to handle the metacognitive developments of pre-service teachers more detailed and on account of both awareness and processes of use. Considering the importance of the issue and little research, this study aims to answer whether the secondary pre-service mathematics teachers' the metacognitive awareness and metacognitive behaviours in the processes of problem solving demonstrate variety according to the variables: the class level and gender. Relevant to this aim, the following research questions were asked;

1. What are the metacognitive awareness levels of the pre-service secondary mathematics teachers in terms of the variables: class level and gender?

2. Does the metacognitive awareness of pre-service secondary mathematics teachers vary according to the class level and gender?

3. Do the emerging frequencies of metacognitive behaviours which the pre-service secondary mathematics teachers demonstrate in the process of problem-solving vary according to class level?

4. Do the emerging order of cognitive and metacognitive behaviours which the pre-service secondary mathematics teachers demonstrate in the process of problem-solving vary according to class level? 


\section{Materials and Methods}

In this study; it is aimed to research the metacognitive awareness of secondary pre-service mathematics teachers and their metacognitive behaviours which they demonstrated during the problem-solving process in detail. For this aim, the research was designed on the basis of partially mixed sequential dominant status design in which data are collected in two steps in order within the scope of mixed methods and that one of the qualitative or quantitative components is more dominant [41]. The second part of the research which is quantitative was mainly focused in this study.

\subsection{Study Group}

In the research process, the study was carried out with 287 pre-service mathematics teachers from the department of secondary mathematics education of a Turkish state university 287 participants took role in the quantitative part and 8 participants each two of whom were from four different classes (first, second, third and fourth) and already participated in the quantitative part took role in the qualitative part. The participant selection process is as follows.

In determining 287 participants studied within the scope of first and second sub-problem; as the sampling unit was universities, the typical case sampling was applied. This method is defined as handling a culture, programme or occasion in terms of typical cases which are not unusual by [38]. In determining this sampling method, it was effective that the aim of collecting information about a general case rather than a specific case considering that not being reached the whole stage. When the university in which the study was carried out, education faculty entry points, the number of current students and student success variables considered, Turkey is in moderate level having no extreme values in its scale. Moreover, a package programme is carried out at the determined university by the Council of Higher Education (CoHE) which is an institution arranging university education programmes in Turkey. Within the scope of the lessons which are being completed in totally 8 terms (4 years $\mathrm{x} 2$ terms), there are two lessons in the 3rd term related to the direct mathematical problem solving 'Mathematics Teaching Through Problem Solving' and in 8th term 'Mathematical Modelling'. As these lessons are optional, only voluntary students enroll them in accordance with the determined quotas.

8 participants, for third and fourth sub- problem, were determined to apply deviant sampling, for a much clear vision of variety related to the study group with a research topic, which is defined as constituting with individuals who reflect diverging cases [38]. For the contrary cases, the total score got from metacognitive awareness scale considered to be the basis. According to this score, it was tried to reach the lowest and the highest scorer participants in each class level. To achieve this, the codes were given to questionnaires presented to the participants. Using the relevant codes, the lowest and the highest scorers were tried to be reached. During this process, two participants from each class and totally 8 having the highest and the lowest score were determined.

The distributions of the participants according to the class level and their score of awareness are summarised in Table 1.

Table 1. The distribution of the Study Groups According to the Sub-Problems

\begin{tabular}{|c|c|c|c|c|c|}
\hline \multirow[b]{2}{*}{ Class Level } & \multirow[b]{2}{*}{ Gender } & \multicolumn{3}{|c|}{$\begin{array}{l}\text { The Participants For The First and } \\
\text { Second Sub-Problem }\end{array}$} & \multirow{2}{*}{$\begin{array}{c}\text { The Participants For The Third and Fourth Sub-Problem } \\
\text { Ascending Score Ranking Place (score) }\end{array}$} \\
\hline & & & $\imath$ & $\%$ & \\
\hline \multirow{2}{*}{ 1st Grade } & Female & 67 & \multirow{2}{*}{90} & \multirow{2}{*}{31.4} & Fourth participant with the lowest score (147) \\
\hline & Male & 23 & & & Second participant with the highest score (237) \\
\hline \multirow{2}{*}{ 2nd Grade } & Female & 62 & \multirow{2}{*}{78} & \multirow{2}{*}{27.2} & Second participant with the lowest score (143) \\
\hline & Male & 16 & & & The participant with the highest score (246) \\
\hline \multirow{2}{*}{ 3rd Grade } & Female & 40 & \multirow{2}{*}{58} & \multirow{2}{*}{20.2} & The participant with the lowest score (156) \\
\hline & Male & 18 & & & The participant with the highest score (244) \\
\hline \multirow{2}{*}{ 4th Grade } & Female & 41 & \multirow{2}{*}{61} & \multirow{2}{*}{21.2} & The participant with the lowest score (114) \\
\hline & Male & 20 & & & The participant with the highest score(221) \\
\hline \multicolumn{3}{|c|}{ Total } & 287 & 100 & 8 \\
\hline
\end{tabular}


As it is shown in Table 1, 90 of the participants were from the first class, 78 of them from the second class, 58 of them for the third class and 61 from the fourth class. Moreover, 210 of the participants were female and 77 of them were male. The voluntariness of the participant was taken into consideration during the study. For this reason, as the lowest scorers in first and second classes and the highest scorer of the first class did not want to attend the rest of the study, it was not possible to continue with them. An interview was carried with the one of the fourth class but its answer was discarded as the participant was so excited and could not present a real problem-solving process. Then its data were ignored and continued with the second participant in the score ranking. Among the participants, two participants from third and fourth class who were the lowest awareness scorers had attended The Mathematics Teaching Through Problem Solving lesson, yet the others had not attended this course. Furthermore, because of the study period, none of the participants were attended to The Mathematical Modelling Course which exists in the 8th term.

\subsection{Data Collection Tools}

Data collection tools used for each sub-problem in data collection process are as follows;

The metacognitive awareness levels and the change of the participants' awareness according to the variables of class level and gender were handled within the scope of first and second sub-problem. Thus, in order to determine the awareness towards metacognition from a general aspect, Metacognitive Awareness Inventory [MAI] which is 5-Point Likert-type scale developed by Schraw and Dennison [26] and translated into Turkish by Akın, Abacı and Çetin[2] was used in this study. This inventory consists of totally 52 items under eight dimensions as; declarative knowledge, procedural knowledge, conditional knowledge, planning, monitoring, evaluation, debugging and information management. . The minimum score from the scale was 52 and the maximum score was 260 . The low score from the inventory shows low metacognitive awareness, higher score shows the highness of the relevant awareness. Reliability coefficient of MAI was determined by Schraw and Dennison[26] as $\propto=.95$; by Akın, Abac1 and Çetin[2] similarly $\propto=.95$ and in this study as $\propto=.91$. As this value was over .70, the data gathered from the scale were considered as reliable and suitable for reporting the analyses [15].

The number and order of cognitive and metacognitive behaviours demonstrated by the participants were considered in terms of third and fourth sub-problem. For this purpose, Multi-Method Interview (MMI) were applied by Wilson[34] during the data collection process. This method, in monitoring metacognitive behaviours, was designed to reduce the mistakes originated from the factors such as; limited linguistic abilities or lack of vocabulary needed to describe their thought process, unnoticed by individuals because of the automatized behaviours or a situation in which not making interview which should be held following the problem solving and the participants' forgetting the solving process in detail. MMI included observation; a problem-based clinical interview (incorporating self-reporting, sometimes 'think aloud' and a card sorting task); video and audio recordings. Wilson[34] defines this method as 'capitalize on the strengths of particular techniques and avoids the disadvantages of each individual method. Cognitive behaviours by Wilson[34] were taken under three categories; awareness, evaluation and regulation. The meanings given these three categories can be summarised as [33];

Awareness; relates to individuals' awareness of where they are in the learning process or in the process of solving a problem, of their content-specific knowledge, and of their knowledge about their personal learning or problem-solving strategies. It also includes their knowledge of what needs to be done, what has been done, and what might be done in particular learning contexts or problem-solving situations. Metacognitive awareness encompasses an individual's cumulative knowledge of acquired competencies and on-going knowledge of mental processes in progress.

Evaluation; refers to judgements made regarding one's thinking processes, capacities and limitations as these are employed in a particular situation or as self-attributes. For example, individuals could be making a judgement regarding the effectiveness of their thinking or of their strategy choice. Such an evaluative function assumes some awareness of the individual's thinking processes and anticipates the possible regulation of those processes

Regulation; occurs when individuals make use of their metacognitive skills to direct their knowledge and thinking. Metacognitive regulation draws upon individuals' knowledge (about self and strategies, including how and why they use particular strategies) and uses executive skills (such as planning, self-correcting, setting goals) to optimise the use of their own cognitive resources.

The use of MMI completed in three stages depending on this base can be summarised as;

- In the first stage; within the scope of clinical interview a problem case is given to the participants and they are asked to solve this problem. Action cards containing totally 14 terms written within the scope of three titles mentioned above, moreover empty cards which the participants about cognitive and metacognitive behaviours in addition to these expressions are given to the participants. It can be asked for the participants think aloud in problem-solving depending on their preferences. The whole process is recorded with a camera. Then, it is asked from the participants to allocate the cards as their used-disused expressions during the problem-solving process and arrange the action cards according to the case of emerging during the problem-solving process.

- In the second stage; to determine whether the card series present solving processes of the participants 
correctly or not, a video record is watched with the participant. In addition, the series of the cards may be changed by the participants at this stage addition and removing may also be applied. Moreover, whether the problem-solving processes reflects the general or not is investigated at the end of this stage.

- In the third stage; when individual's problem solving process within the scope of research does not represent the general, it is aimed to put forth its reasons. Therefore, an interview is arranged with the participant for the reasons of the relevant discrepancy a week later.

After determining the method to be used in data collection process, the mathematical problem was determined. Then, it was decided that choosing a non-routine problem would be appropriate. Hence, during solving, participants, coming across with a sort of problem containing no principle or concept that they do not know but less familiar, enables the emerging of thought processes and observing the metacognitive behaviours ([52]:[33]; [10,11]). At the end of the literature analyses, 15 different problems which were applied in previous studies and Mathematical Olympiads, were determined. These problems were analysed by two different experts, one of them studied on metacognition in the process of mathematical modelling and another on cognitive behaviours in the mathematical modelling process and second and fourth classes who were among the participants but not among the eight participants. To include in the data collection process, the problem was determined as below;

Watermelon Problem: A farmer takes his totally 300 kilos of watermelons to a festival. The water content of the watermelons is $99 \%$. The festival is postponed for three days. The weight of the watermelons under the sun reduces and the water content of the new weight is $98 \%$. How many kilos do the watermelons weigh totally in the final situation?

Determining the problem, in order to specify the availability of the method for the study group and metacognitive activity cards to be used during the process, a pilot study was conducted with two distinctive participants. During this process, from the participants' expressions in the metacognitive behaviours, which also existed in the action cards and from the agreement of two experts on the availability of the cards, the metacognitive cards by Wilson[34] were decided to use in the research.

Awareness:

I thought about what I already know

I tried to remember if I had ever done a problem like this before

I thought about something I had done another time that had been helpful

I thought 'I know what to do'

I thought 'I know this sort of problem'

Evaluation:

I thought about how I was going

I thought about whether what I was doing was working

I checked my work

I thought 'Is this right?'

I thought 'I can't do it'

Regulation:

I made a plan to work it out.

I thought about a different way to solve the problem.

I thought about what I would do next.

I changed the way I was working.

At the end of this stage, question/questions to be asked during the interview were determined in order to understand whether the metacognitive behaviours which the participants demonstrated during the process of problem solving represent the general. Taking an expert's opinion conducting research on metacognitive behaviours during the mathematical modelling process and having experience on quantitative research, a written answer was decided to be given to the following question by the participants.

'Describe the solving process of a mathematical problem you encountered in detailed.'

Accordingly, an open-ended questionnaire was prepared for the participants at the end of the interview.

\subsection{Collecting Data}

The data collection process was completed in two stages. In the first stage, MAI was presented to the participants to demonstrate metacognitive awareness of the participants qualitatively. To maintain the comfort for participants to express their opinions, they were not asked to write their personal identities on the papers. Then, each code was given to the each questionnaire to reach the relevant codes and participants were asked to save this code It took about ten minutes for the participants to fill the MAI and they did not interact with each other during the time. At the end of the period, each form was collected and archived.

In the second stage, metacognitive behaviours that the participants represent during the problem-solving process were observed on the basis of MMI. The determined question was asked to solve by determined participants from each class level. All of the participants expressed that they did not encounter with this problem before. Participants were told to think aloud during the solving process if they want. The duration of participants struggling with the problem differed from 1 minute 1 second to 20 minutes 5 seconds, the average duration was 9 minutes 33 seconds. The problem-solving process was videotaped with a camera. Previously determined metacognition cards were presented to the participants to analyse at the end of the process and asked to set apart according to using or discussing. Furthermore, the empty cards were given to the participants to write the cognitive behaviours that they use during the solving attempt and their metacognitive behaviours (if there were) which were not in the cards. Then, the participants were asked to put the cognitive and 
metacognitive cards in order according to their occurring sequence. After this activity, the interview videos were watched by the participants, the sequence of the behaviour cards and solving process were matched exactly. After investigating the video records;

- $\quad$ One of the participants did not make any change in the first statement,

- One of the participants added one card to the statement and deleted one card,

- One of the participants added a card to the first statement,

- $\quad$ One of the participants changed the place of a card in the first statement,

- $\quad$ One of the participants changed the place of a card in the first statement,

- One of the participants made no change on the first statement,

- One of the participants added two cards to the first statement and changed the place of two cards,

- One of the participants added two cards to the first statement and changed the place of two cards,

With this form, each participant made replacements on their card sequences.

Then, the participants were asked to fill out previously prepared open-ended questionnaire aimed to show whether the solving process that the participants expressed represented the general or not.

The answers of the MAI, the records related to the problem-solving process, the orders of the behaviour cards and answers to the open-ended questionnaire were transferred into computer and data were prepared for the analysis.

\subsection{Analysing the Data}

The data analysis was as follows: In order to represent the metacognitive awareness levels of the participants within the scope of the first sub-problem 5 point Likert-type scale, dividing each item into three equal parts, it was separated into three levels as; 1-2,333 low, 2,334-3,666 medium and $3,667-5$ high. With multiplying these limits with number of items in the scale, participants, according to their total score from the scale, classified as having awareness of; 52-121,316 points low, 121,368-190,632 medium and 190,684- 260 high. The findings were presented in the tables and figures.

Within the scope of second sub-problem, to determine whether the metacognitive awareness of the participants varies according to class level and gender or not, the 5 Point Likert-type data from MAI were used. The characteristics of collected data according to the parametric test conditions were as follows.

- $\quad$ Participants are independent.

- Statistical values related to the distribution of the data variations were shown in Table 2 .

Table 2. Test of homogeneity of variances results of the data gathered from MAI

\begin{tabular}{|c|c|c|c|c|}
\hline & $\begin{array}{c}\text { Levene } \\
\text { Statistic }\end{array}$ & $d f 1$ & $d f 2$ & Sig. \\
\hline class level &, 500 & 3 & 283 &, 683 \\
\hline gender &, 245 & 1 & 285 &, 621 \\
\hline
\end{tabular}

As it is presented in Table 2, the distributions of the variations according to categories of variables are homogenous.

The statistical values related to the data distribution were as follow;

As it is presented in the Table 3, the data showed normal distribution. Although the value of Shapiro- Wilk represented a significant level in the fourth class according to the class level, from the value of Skewness and Kurtosis as \pm 2, normal distribution was reported. Moreover, analysing Q-Q plots, it was noticed that values were over the diagonal line or very close. Analysing Boxplots, it was noticed that there was no outlier value. From these results, it can be said that the data distributed statistically and graphically normal.

Table 3. The data related to the distributions of data collected with MAI

\begin{tabular}{|c|c|c|c|c|c|c|c|c|}
\hline & & \multicolumn{2}{|c|}{ Skewness } & \multicolumn{2}{|c|}{ Kurtosis } & \multicolumn{3}{|c|}{ Shapiro-Wilk Test } \\
\hline & & Statistic & Std. Error & Statistic & Std. Error & Statistic & $d f$ & sig. \\
\hline \multirow{4}{*}{ Class Level } & 1st Grade &,- 262 &, 254 & ,470 &, 503 & ,985 & 90 & ,371 \\
\hline & 2nd Grade &,- 021 & ,272 &,- 084 &, 538 & ,993 & 78 & ,964 \\
\hline & 3rd Grade &, 140 &, 314 &,- 181 & ,618 & ,990 & 58 & ,904 \\
\hline & 4th Grade &,- 976 & ,306 & 1,286 & ,604 & ,941 & 61 & ,006 \\
\hline \multirow{2}{*}{ Gender } & female &,- 409 &, 168 & ,614 &, 334 & ,989 & 210 & ,101 \\
\hline & male &,- 188 & ,274 & ,111 & ,541 & ,977 & 77 & 181, \\
\hline
\end{tabular}


As the parametric test conditions ensured, in order to determine whether there is a significant difference of metacognitive awareness among the participants on account of gender and class level or not, the Two-way ANOVA test was applied. Gathered findings were demonstrated by using tables.

Within the scope of the third and fourth sub-problem, frequencies and sequence of metacognitive behaviours applied during the solving process, with the requirement of MMI, were determined analysing the mentioned process by the participants. Relevant problem solving processes and sequences were described by the participants as they were. In the second stage of the analysis process related to this sub-problem, it was aimed to determine the matching level of problem solving processes of participants within the scope of general and this problem. In the open-ended questionnaire, the general problem solving processes expressed by each participant and solving stages represented by the participant in this research were compared. This stage of the analysis was carried out simultaneously with the participant and an expert who is capable of metacognition and quantitative research. The compare results reached at the end of the agreement, it was coded as follow: substantially coinciding (the situation of maximum two behaviour in which the participant describe in general process but do not represent during the process of problem solving or just the opposite) and entirely coinciding (the situation of the whole behaviours of participant describe in general process and in this problem solving process are both same). For example, one of the participants expressed that though she never checked the results during the problem solving process, she revised the result she reached within the research. From this variety, it was coded as entirely coincide that the solving process belonging to the participant with general problem solving process.

\section{Findings}

In this section, the findings related to the sub-problems of the research were presented in order.

\subsection{The findings related to the first sub-problem about the metacognitive awareness levels of the participants in terms of the class level and gender?}

From the total score of the participants from MAI, according to the classification 52-121,316 low, 121,368-190,632 medium and 190,684-260 high, distribution of metacognitive awareness levels are presented in Table 4.

As shown in Table 4, while maximum awareness level rate is seen mainly in third class $(62 \%)$ the minimum is in second class $(44,8)$. Considering the gender variable the distribution among female (low:0,5-medium:47,6-high: 51,9) and male (medium:47.4-high:52.6) is almost same. Only one of the participants in fourth class $(0,3 \%)$ metacognitive awareness level can be considered as low. In general, $48 \%$ of the participants had medium and $52 \%$ had higher level of awareness.

Table 4. The distributions of participants metacognitive awareness levels as low, medium and high according to gender and class level

\begin{tabular}{|c|c|c|c|c|c|c|c|}
\hline \multirow{2}{*}{$\begin{array}{c}\text { Class } \\
\text { Level }\end{array}$} & \multirow{2}{*}{ Gender } & \multicolumn{2}{|c|}{ Low } & \multicolumn{2}{c|}{ Medium } & \multicolumn{2}{c|}{ High } \\
\cline { 2 - 8 } & & $\mathrm{f}$ & $\%$ & $\mathrm{f}$ & $\%$ & $\mathrm{f}$ & $\%$ \\
\hline \multirow{3}{*}{$\begin{array}{c}\text { 1st } \\
\text { Class }\end{array}$} & Female & - & - & 35 & 38,9 & 32 & 35,6 \\
\cline { 2 - 8 } & Male & - & - & 13 & 14,4 & 10 & 11,1 \\
\cline { 2 - 8 } & Total & - & - & 48 & 53,3 & 42 & 46,7 \\
\hline \multirow{3}{*}{$\begin{array}{c}\text { 2nd } \\
\text { Class }\end{array}$} & Female & - & - & 34 & 43,6 & 28 & 35,8 \\
\cline { 2 - 8 } & Male & - & - & 9 & 11,5 & 7 & 9 \\
\cline { 2 - 8 } & Total & - & - & 43 & 55,1 & 35 & 44,8 \\
\hline \multirow{3}{*}{$\begin{array}{c}\text { 3rd } \\
\text { Class }\end{array}$} & Female & - & - & 14 & 24,1 & 26 & 44,8 \\
\cline { 2 - 8 } & Male & - & - & 8 & 13,8 & 10 & 17,2 \\
\cline { 2 - 8 } & Total & - & - & 22 & 37,9 & 36 & 62 \\
\hline \multirow{3}{*}{$\begin{array}{c}\text { 4th } \\
\text { Class }\end{array}$} & Female & 1 & 1,7 & 17 & 27,9 & 23 & 37,7 \\
\cline { 2 - 8 } & Male & - & - & 7 & 11,5 & 13 & 21,3 \\
\cline { 2 - 8 } & Total & 1 & 1,7 & 24 & 39,3 & 36 & 59 \\
\hline
\end{tabular}

\subsection{The Findings related to the second sub-problem} about the difference of the metacognitive awareness of the participants in terms of the class level and gender?

Data related to the metacognitive awareness of the participants was acquired with the MAI application. Considering the whole group of the participants minimum score was determined as 114 and maximum point as 246 . The distributions of the descriptive data according to the gender and class level acquired from this scale were presented in Table 5 .

Table 5. The descriptive findings according to gender and class level

\begin{tabular}{|c|c|c|c|c|}
\hline class level & gender & $\mathrm{n}$ & $\bar{x}$ & SS \\
\hline \multirow{3}{*}{ 1st Class } & Female & 67 & 192,7701 & 21,48460 \\
\hline & Male & 23 & 181,8609 & 24,38535 \\
\hline & Total & 90 & 189,9822 & 22,63158 \\
\hline \multirow{3}{*}{ 2nd Class } & Female & 62 & 188,2887 & 20,65814 \\
\hline & Male & 16 & 192,5000 & 29,20274 \\
\hline & Total & 78 & 189,1526 & 22,51978 \\
\hline \multirow{3}{*}{ 3rd Class } & Female & 40 & 197,4000 & 18,62284 \\
\hline & Male & 18 & 194,3778 & 19,84243 \\
\hline & Total & 58 & 196,4621 & 18,88667 \\
\hline \multirow{3}{*}{ 4th Class } & Female & 41 & 190,4293 & 24,26098 \\
\hline & Male & 20 & 193,6000 & 20,65353 \\
\hline & Total & 61 & 191,4689 & 23,01585 \\
\hline \multirow{3}{*}{ Total } & Female & 210 & 191,8719 & 21,40119 \\
\hline & Male & 77 & 190,0468 & 23,75863 \\
\hline & Total & 287 & 191,3822 & 22,03080 \\
\hline
\end{tabular}


As it is seen in Table 5, the average metacognitive awareness scores according to the class level varied: 189,1526 and 191,4689. As the gender variable considered, the average relevant scores for female participants were as; 191,8719 and for male participants as; 190,0468. From the basis of the average varieties among the sub-groups related to the variables can easily be noticed. In order to determine whether the relevant varieties were statistically significant or not, applied Two-way ANOVA results are presented in Table 6.

Table 6. Two-way ANOVA results

\begin{tabular}{|c|c|c|c|c|c|}
\hline Source & $\begin{array}{c}\text { Type III } \\
\text { Sum of } \\
\text { Squares }\end{array}$ & df & $\begin{array}{c}\text { Mean } \\
\text { Square }\end{array}$ & F & Sig. \\
\hline $\begin{array}{c}\text { Class } \\
\text { level }\end{array}$ & 2189,705 & 3 & 729,902 & 1,517 &, 210 \\
\hline gender & 146,914 & 1 & 146,914 &, 305 &, 581 \\
\hline $\begin{array}{c}\text { Class } \\
\text { level } * \\
\text { gender }\end{array}$ & 2217,094 & 3 & 739,031 & 1,536 &, 205 \\
\hline
\end{tabular}

Table 6 showed that the scores gathered from metacognitive awareness test represented a significant variety according to the variables of class level $\left(\mathrm{F}_{(3,283}\right)=$ $1,517, \mathrm{p}>.05)$ and gender $\left(\mathrm{F}_{(1,285)}=, 586 ; \mathrm{p}>, 05\right)$. In other words, these two variables had no meaningful effect on the metacognitive awareness of participants alone. Furthermore, the mutual effect of these two variables was not effective on the metacognitive awareness of the participants $\left(\mathrm{F}_{(3,283)}=\right.$ $1,536, \mathrm{p}>.05)$.

\subsection{The findings related to the third about the emerging frequencies of metacognitive behaviours showed in the problem-solving process and the fourth sub-problem about the emerging order of cognitive-metacognitive behaviours in the class level}

In order to find solutions to these sub-problems, the findings from interviews with the participants who got the lowest and the highest scores on were presented orderly. In order to use in the presentation of findings, coding was made belonging to the participants as; K.X(Class Level).X(Awareness Level; 1 low, 2 high). For instance; the participant who is in second class and has low awareness score was coded as K.2.1. The solving process of each participant and their metacognitive behaviours during that process were presented below in detail.

\section{- The Solving Process of K.1.1 Coded Participant}

K.1.1 coded participant completed the solving process in 1 minute 1 second but could not solve the problem correctly. His solution and behaviours during the solving process were shown in Table 7.
Table 7. The problem solving process of K.1.1 coded participant

\begin{tabular}{|c|l|c|}
\hline Duration & Observed Behaviour & $\begin{array}{c}\text { Participant's Solving } \\
\text { Process }\end{array}$ \\
\hline 0:00-0:16 & $\begin{array}{l}\text { He started to read the } \\
\text { problem. (at 0:05, 'I } \\
\text { think I can solve the } \\
\text { problem now' he said.) }\end{array}$ & \\
\hline 0:17-1:01 & $\begin{array}{l}\text { He claimed that he could } \\
\text { solve through direct } \\
\text { proportion. He described } \\
\text { the setting up the } \\
\text { proportion verbally. } \\
\text { Then he wrote the } \\
\text { proportion and made the } \\
\text { operation. At the end of } \\
\text { the period finished the } \\
\text { solving process saying } \\
\text { 'enough'. }\end{array}$ \\
\hline
\end{tabular}

The sequence of action cards of K.1.1 coded participant showing the solving process was showed below;

\begin{tabular}{|c|c|c|}
\hline & & BEGINNING \\
\hline 8 & (A) & I thought 'I know what to do'. \\
\hline 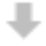 & (A) & I thought 'I know this sort of problem'. \\
\hline 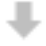 & (A) & I thought about what I already know. \\
\hline 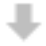 & (R) & I made a plan to work it out. \\
\hline$\sqrt{1}$ & (A) & $\begin{array}{l}\text { I thought about something I had done another time } \\
\text { that had been helpful. }\end{array}$ \\
\hline 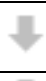 & (A) & $\begin{array}{l}\text { I tried to remember if I had ever done a problem like } \\
\text { this before. }\end{array}$ \\
\hline 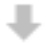 & (C) & I set up direct proportion. \\
\hline 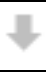 & (E) & $\begin{array}{l}\text { I thought about whether what I was doing was } \\
\text { working. }\end{array}$ \\
\hline 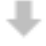 & (E) & I thought about how I was going. \\
\hline 8 & (E) & I checked my work. \\
\hline \multirow[t]{2}{*}{ 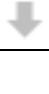 } & (E) & I thought 'Is this right?'. \\
\hline & & SOLUTION \\
\hline
\end{tabular}

Figure 2. The sequence of action cards of K.1.1

As it is stated in Table 7, after the analysis of the solving process of K.1.1 coded participant, it can be reported that he reached the solution following the first way of working out in which he evaluated what he know about it. As it is stated in Figure 2, participant, in this process, demonstrated totally 11 behaviours as; within the scope of awareness 5 , of evaluation 4 , regulation 1 and cognitive behaviour. The description of K.1.1 coded participant's related to the general problem solving is as follows;

'Generally, I, starting to glance at the problem and, considering what it requires, find the solution. At the stage of checking solution, I check whether I did a mistake, if there is, try to find out understanding mistakes of problem.' 
Generally, compared the statement of K.1.1 coded participant on problem-solving process with behaviours during problem solving were coded as entirely coinciding. He specifically checked solution only in terms of operations but he did not check the results' validity for problem situation.

\section{- $\quad$ The Solving Process of K.1.2 Coded Participant}

The K.1.2 coded participant tried to solve the problem in 20 minutes 5 seconds but finished the process expressing she could not reach the solution. Her struggles related to study process and behaviours in solving process were shown in Table 8.

Table 8. The problem solving process of K.1.2 coded participant

\begin{tabular}{|c|c|c|}
\hline Duration & Observed Behaviour & Participant's Solving Process \\
\hline 0:00-0:24 & She read the problem. & \multirow{11}{*}{ 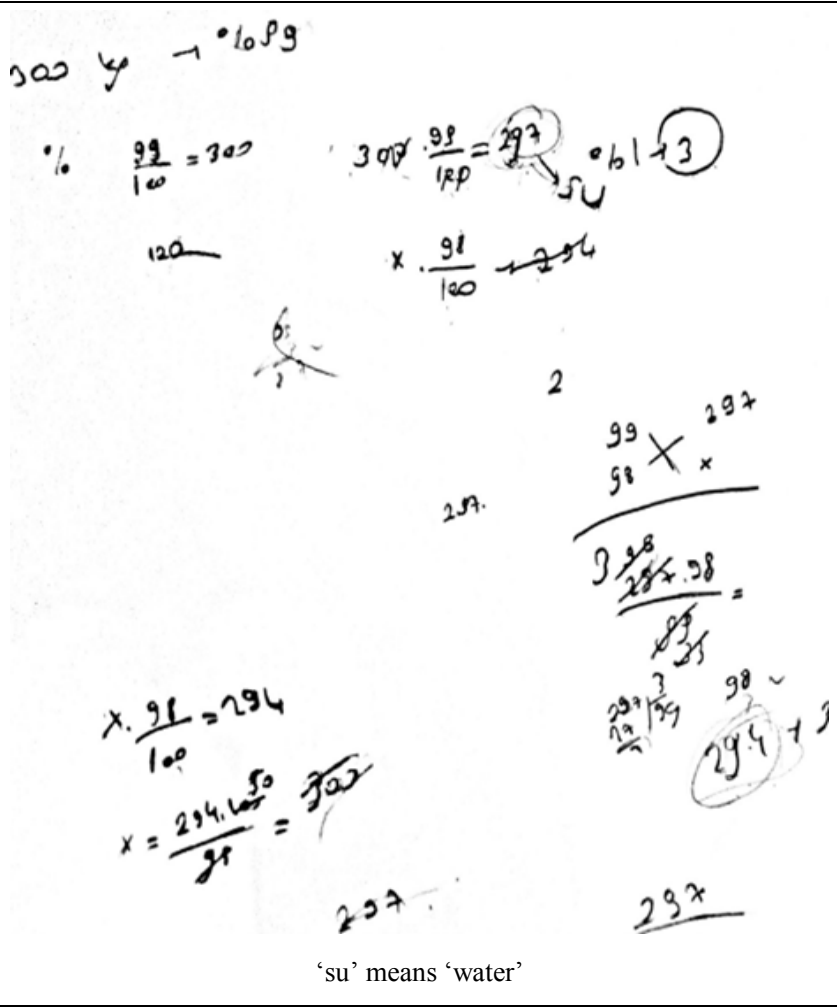 } \\
\hline $0: 25-1: 22$ & $\begin{array}{l}\text { She thought silently. Then she read the problem again. } \\
\text { She expressed what she understood from the problem. } \\
\text { Again, she read the problem several times. }\end{array}$ & \\
\hline $1: 23-2: 03$ & $\begin{array}{l}\text { She wrote the values in the problem. Then she read the } \\
\text { problem several times and 'I have no idea' she said. }\end{array}$ & \\
\hline 2:01-2:30 & She continued thinking about the problem. & \\
\hline 2:31-2:50 & $\begin{array}{l}\text { Using the values in the problem, she wrote an } \\
\text { expression as } 98 / 100=300 \text { and } 100 \text { stroke out } 100 .\end{array}$ & \\
\hline $2: 51-4: 46$ & She read the problem several times without operation. & \\
\hline $4: 17-5: 10$ & $\begin{array}{l}\text { She calculated the water amount. Then, she wrote an } \\
\text { expression of x. } 98 / 100 \text {. 'I do not know where to equate } \\
\text { this' she said. }\end{array}$ & \\
\hline 5:11-6:05 & $\begin{array}{l}\text { Again she read the problem. She thought doing } \\
\text { nothing. She underlined the values in the problem and } \\
\text { thought. }\end{array}$ & \\
\hline 6:06-6:58 & $\begin{array}{l}\text { Thinking the reducing is } 1 \% \text { in watermelons expressed } \\
\text { the reducing amount as } 3 \mathrm{~kg} \text {. }\end{array}$ & \\
\hline $6: 59-7: 48$ & $\begin{array}{l}\text { She returned to the problem. She expressed what she } \\
\text { understood. She thought. }\end{array}$ & \\
\hline 7:49-8:00 & $\begin{array}{l}\text { Returning to her previous thought'297-3=294 perhaps, } \\
\text { I say' }\end{array}$ & \\
\hline $8: 01-8: 12$ & \multicolumn{2}{|c|}{ The researcher expressed that she would finish the interview if she reached the solution. } \\
\hline $8: 13-8: 31$ & \multicolumn{2}{|c|}{ She read the problem again. She made operations. Then, she stroke out what she wrote. } \\
\hline $8: 32: 11: 07$ & \multicolumn{2}{|c|}{$\begin{array}{l}\text { She read the problem several times. She expressed what she understood with her own expressions. Then, again she read several } \\
\text { times. At the end of the period, she said 'I have no other solution in my mind'. }\end{array}$} \\
\hline 11:08-11:40 & \multicolumn{2}{|c|}{$\begin{array}{l}\text { She thought silent. 'Actually I am not sure. I did but when I saw I thought how I could solve. But I am not sure whether it is correct.' } \\
\text { She said. She expressed that she could not understand what to do, if she remembered a different way she would apply on it. }\end{array}$} \\
\hline 11:41-12:58 & \multicolumn{2}{|c|}{$\begin{array}{c}\text { She examined and thought about what she wrote the values in the problem. She expressed what she understood with her own } \\
\text { expressions. }\end{array}$} \\
\hline 12:59-14:02 & \multicolumn{2}{|c|}{$\begin{array}{l}\text { She settled a proportion (A proportion as; while the amount of water is } 99 \% \text { the weight is } 297 \mathrm{~kg} \text {, then what is the weight if it is } 98 \% \text { ). } \\
\text { With the operation, she found the amount of water as } 294 \mathrm{~kg} \text {. She added the } 3 \mathrm{~kg} \text { in the watermelon and calculated the amount as } \\
297 \mathrm{~kg} \text {. }\end{array}$} \\
\hline 14:03-14:44 & \multicolumn{2}{|c|}{ 'I find $297 \mathrm{~kg}$ but I think it is incorrect' she said. At the end of the period she expressed that she had no idea of solving it. } \\
\hline 14:45-16:00 & \multicolumn{2}{|c|}{$\begin{array}{l}\text { She returned to the problem thinking for a while. She read the problem and analysing what she wrote, tried to find out the relation } \\
\text { between them. }\end{array}$} \\
\hline 16:01-16:55 & \multicolumn{2}{|c|}{ She settled the equation as $x .98 / 100=294$. At the end of the process, she reached a result as $x=300$. } \\
\hline 16:56-17:07 & \multicolumn{2}{|c|}{$\begin{array}{c}\begin{array}{l}\text { She expressed that she followed the wrong way saying the result was incorrect. 'There must definitely be reduce in the weight' she } \\
\text { said. }\end{array}\end{array}$} \\
\hline 17:08-18:12 & \multicolumn{2}{|c|}{ She reviewed all the operations she made before. First reviewed the problem and then the last solution again. } \\
\hline 18:13-18:20 & \multicolumn{2}{|c|}{ She wrote 297 saying 'let me try something' and said something silently and stroke out it. } \\
\hline 18:21-18:34 & \multicolumn{2}{|c|}{ The researcher asked him/her to express the process clearer. } \\
\hline 18:35-20:05 & \multicolumn{2}{|c|}{$\begin{array}{l}\text { She thought silently and said 'I do not know the way to follow. This way looks like as if incorrect, too'. She read the problem again. } \\
\text { She thought and analysed all the expressions he wrote. She expressed that there was a mistake somewhere. She continued analysing. } \\
\text { At the end of the process, she claimed that the result was } 297 \text { but not sure and she would not solve it. }\end{array}$} \\
\hline
\end{tabular}


The sequence of action cards of K.1.2 coded participant showing the solving process was shown below;

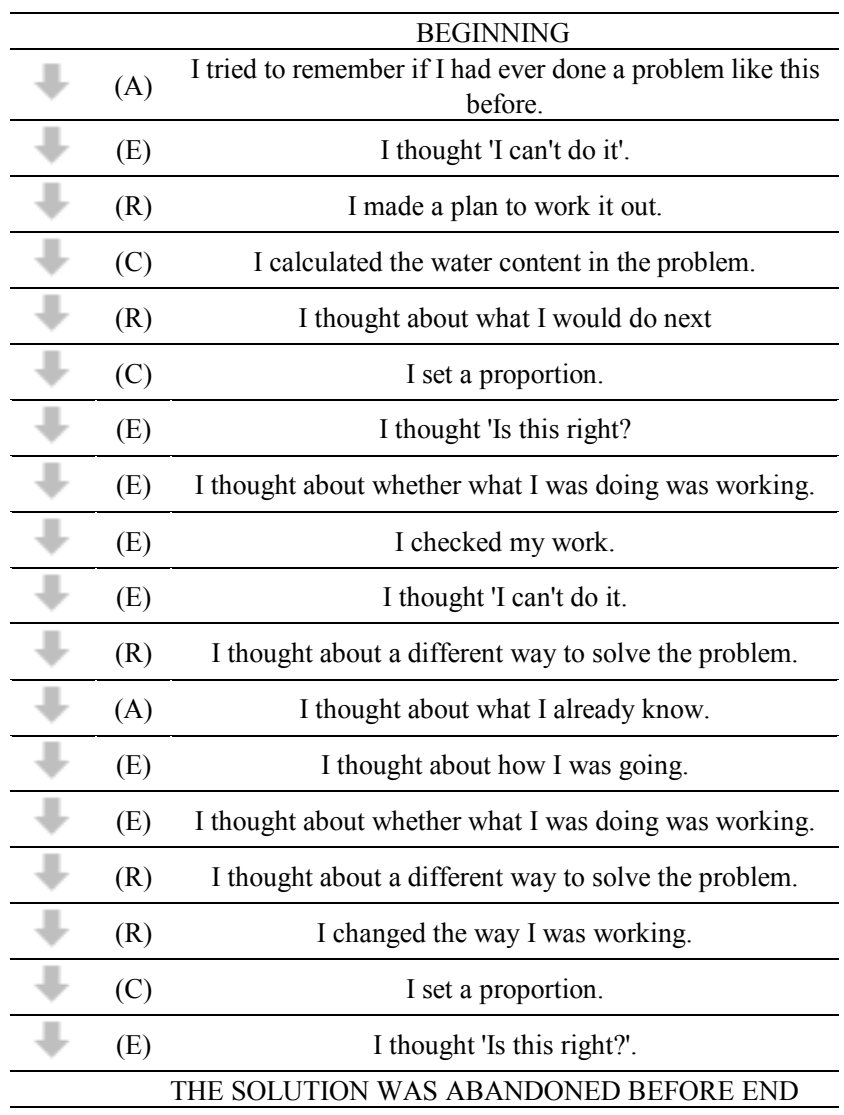

Figure 3. The sequence of action cards of K.1.2
As it is stated in Table 8, when the solving process of K.1.2 coded participant was analysed, it can be claimed that she tried to solve the problem in accordance with a previous problem she had solved. She abandoned the process after trying a few ways. As it is shown in Figure 3, she demonstrated 18 behaviours in this process; within the scope of awareness 2, evaluation 8, regulation 5 and cognitive behaviours 3. The description of K.1.2 coded participant related to general problem-solving was as follows;

'I start the problem-solving process thinking of if I have solved such problem. I try to resemble them. I think about a way of evaluating the data. I try just like this. If it does not, I think of another way. If I cannot remember another way, after a new evolution, mostly I think I cannot reach the correct solution at the end if I do not remember at the beginning. I evaluate again from the beginning. I continue looking for another way. I stop thinking if I am not sure.'

When the expression of K.1.2 coded participant on problem-solving process in general was compared with behaviours which she demonstrated during problem solving process, it was coded as entirely coinciding. The participant reached at different solutions following different ways she tried, thought about whether the results were correct or not and abandoned the process before giving an result which he thought that it was incorrect.

\section{- $\quad$ The Solving Process of K.2.1 Coded Participant}

K.2.1 coded participant finished the solving process in 7 minutes 54 seconds and could not solve the problem correctly. The solution and behaviours during the process were shown in Table 9.

Table 9. The problem solving process of K.2.1 coded participant

\begin{tabular}{|c|c|c|}
\hline Duration & Observed Behaviour & Participant's Solving Process \\
\hline $0: 00-0: 31$ & She read the problem (twice) & \multirow{11}{*}{ 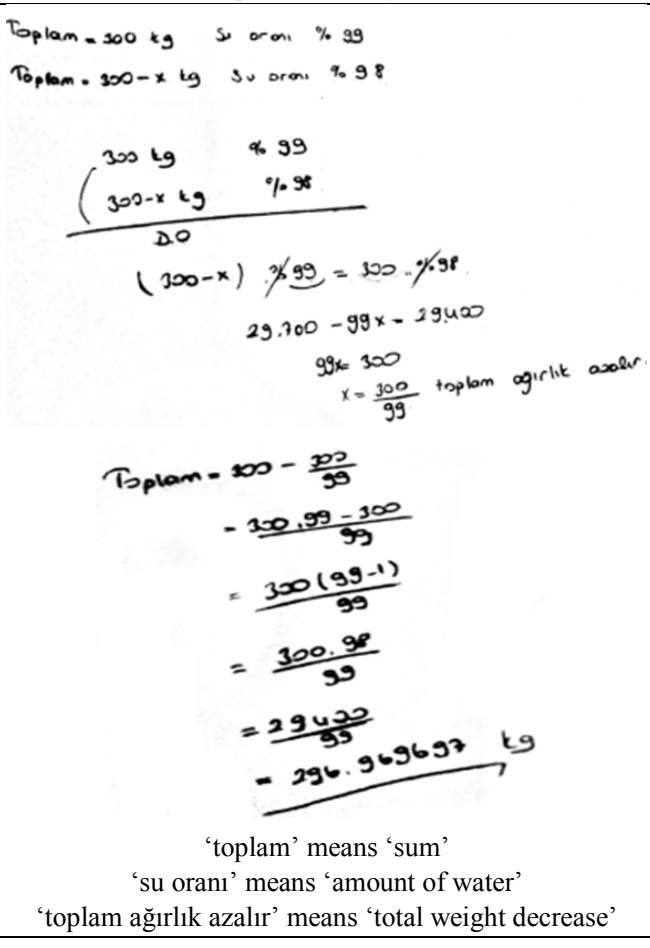 } \\
\hline $0: 32-0: 59$ & $\begin{array}{l}\text { She read the problem again and expressed not to } \\
\text { understand it. }\end{array}$ & \\
\hline $1: 00-1-56$ & $\begin{array}{l}\text { She wrote the values in the problem and expressed what } \\
\text { he understood using variable. She repeated what it } \\
\text { wanted in the problem. }\end{array}$ & \\
\hline $1-57-3: 00$ & $\begin{array}{l}\text { She silently examined the problem and things she wrote } \\
\text { again. At the end of this process, she claimed that she } \\
\text { would solve it using proportion. }\end{array}$ & \\
\hline $3: 01-3: 20$ & $\begin{array}{l}\text { She wrote the expressions she would use in the } \\
\text { proportion. She tried to determine the sort of proportion } \\
\text { (direct or indirect proportions). }\end{array}$ & \\
\hline $3: 21-3: 26$ & $\begin{array}{l}\text { Saying;'just a minute, why the total amount changes' } \\
\text { she thought of the expressions in proportion. }\end{array}$ & \\
\hline $3: 27-6: 02$ & $\begin{array}{l}\text { She found out the value of } \mathrm{x} \text { variable making the } \\
\text { calculations. (3:44 'I don't know what I do' she said.) }\end{array}$ & \\
\hline $6: 03-6: 47$ & $\begin{array}{l}\text { Deducing } x=300 / 99 \text { (reducing amount on account of } \mathrm{kg} \text { ) } \\
\text { from } 300 \text { she tried to reach the solution. } 6: 42-6: 46: \text { ' } \mathrm{I} \\
\text { am getting an entirely incorrect solution') she said. }\end{array}$ & \\
\hline $6: 48-6: 55$ & She determined the mistake she made. & \\
\hline $6: 56-7-51$ & She had the correct solution. & \\
\hline $7: 52-7: 54$ & $\begin{array}{l}\text { She finished the process saying 'I think this is the correct } \\
\text { solution, I finished'. }\end{array}$ & \\
\hline
\end{tabular}


The sequence of action cards of K.1.2 coded participant showing the solving process was shown below;

\begin{tabular}{|c|c|c|}
\hline \multicolumn{3}{|r|}{ BEGINNING } \\
\hline 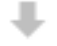 & (E) & I thought 'I can't do it'. \\
\hline & (A) & $\begin{array}{l}\text { I tried to remember if I had ever done a problem like this } \\
\text { before. }\end{array}$ \\
\hline & (A) & $\begin{array}{l}\text { I thought about something I had done another time that } \\
\text { had been helpful. }\end{array}$ \\
\hline & (A) & I thought about what I already know. \\
\hline$\sqrt{2}$ & (A) & I thought 'I know what to do'. \\
\hline & (C) & I wrote what I understand from the problem on a paper. \\
\hline 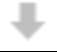 & (C) & I did operations. \\
\hline & (R) & I thought about a different way to solve the problem. \\
\hline$\sqrt{2}$ & (C) & I continued with proportion considering no other way. \\
\hline & (E) & I thought about whether what I was doing was working. \\
\hline & (C) & I did multiplication considering the divisibility rules. \\
\hline$\sqrt{2}$ & (E) & I thought about how I was going. \\
\hline$\sqrt{2}$ & (E) & I checked my work. \\
\hline$\sqrt{2}$ & (C) & I noticed the mistakes and made corrections. \\
\hline$v$ & (R) & I thought about what I would do next. \\
\hline$\sqrt{2}$ & (E) & I checked my work \\
\hline & & SOLUTION \\
\hline
\end{tabular}

Figure 4. The sequence of action cards of K.2.1

As it is stated in Table 9, after the analysis of the solving process related to the K.2.1 coded participant, it was understood that she started the process thinking of she could not solve the problem at first. She evaluated her previous knowledge about the problem and solved it through a way she determined. As it is shown in Figure 4, the participant, in this process, demonstrated totally 16 behaviours; within the scope of awareness 4, evaluation 5, regulation 2 and cognitive behaviour 5. The description of K.2.1 coded participant related to general problem-solving process was as follows;

'Generally like this. I believe that the first thing I remember is correct and continue through is. I never check the result. I checked my answers in high school entrance exam and changed some of them. All of my changes were incorrect answers and the previous answers were correct. So, I could not enter the high school I wanted. I no longer check my answers again, also gave correct answers to all the questions in university exam.'

When the expression of K.2.1 coded participant on problem-solving process in general compared with behaviours she demonstrated during problem-solving process, it was coded as entirely coinciding. The participant used an expression during the solving process as; 'I don't know what I do'. She did not check the result intentionally. She stated this situation originated from a negative experience that she had changed the results after checking and the latter results were entirely incorrect. However, analysing the operations during 6:42-6:46 process, expressing 'I am getting an entirely incorrect solution' reported the solution was incorrect and immediately after she defined the mistake. Therefore, it can be pointed out that the participant checked the results not in the end but during the process.

\section{- $\quad$ The Solving Process of K.2.2 Coded Participant}

K.2.2 coded participant finished the solving process in 4 minutes 36 seconds and could solve the problem correctly. The solution and behaviours during the process were shown in Table 10.

Table 10. The solving process of K.2.2 coded participant

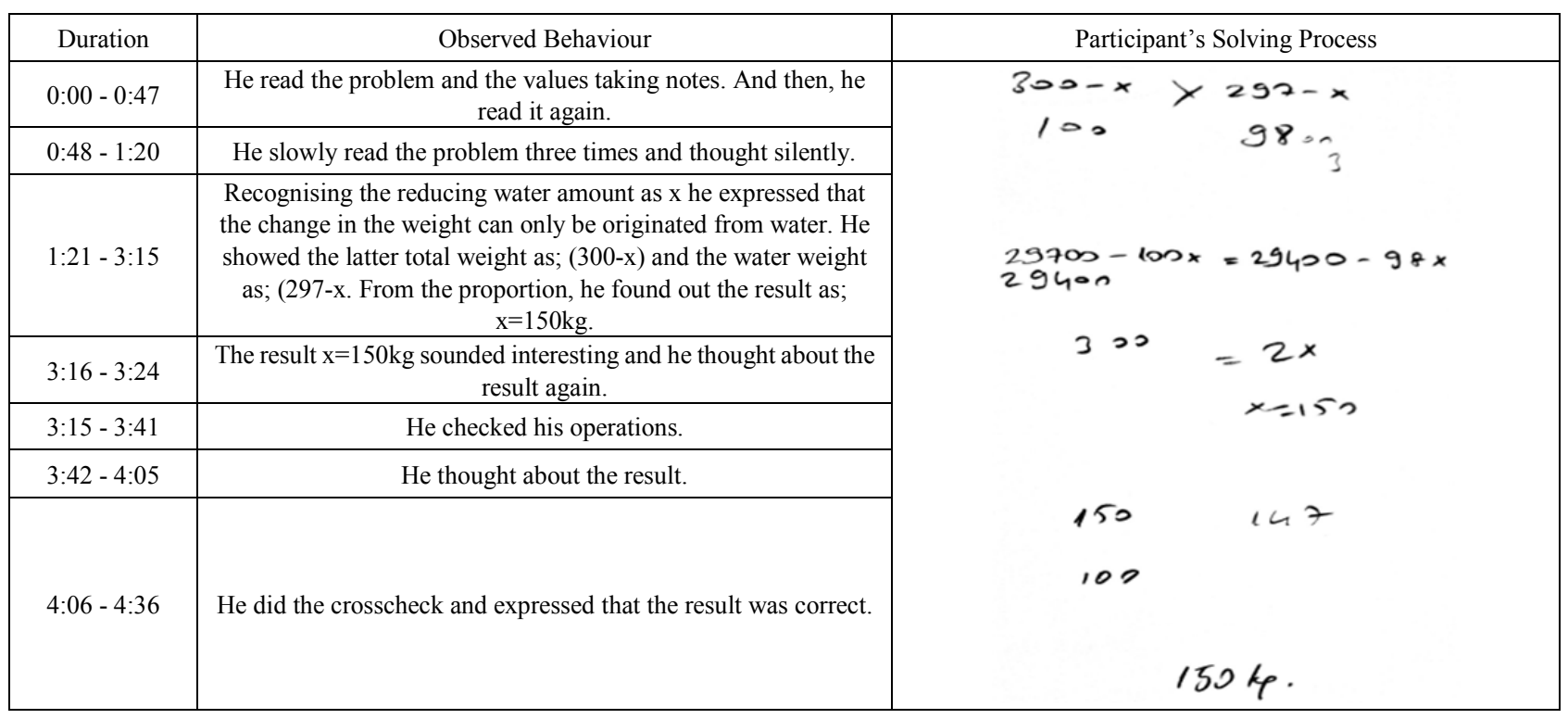


The sequence of action cards of K.2.2 coded participant showing the solving process was shown below;

\begin{tabular}{|c|c|c|}
\hline & & BEGINNING \\
\hline$\sqrt{2}$ & (A) & I thought 'I know what to do'. \\
\hline$\sqrt{7}$ & (A) & I thought 'I know this sort of problem'. \\
\hline$\sqrt{v}$ & (C) & I wrote the data in the problem. \\
\hline$\sqrt{v}$ & (C) & I set direct proportion. \\
\hline$\sqrt{2}$ & (E) & I thought about how I was going. \\
\hline 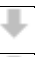 & (R) & I thought about what I would do next. \\
\hline 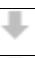 & (R) & I made a plan to work it out. \\
\hline$\sqrt{2}$ & (C) & I set direct proportion. \\
\hline$\sqrt{2}$ & (E) & I checked my work. \\
\hline $\bar{v}$ & (E) & I thought 'Is this right?'. \\
\hline & & SOLUTION \\
\hline
\end{tabular}

Figure 5. The sequence of action cards of K.2.2

As it is shown in Table 10, from the analysis of the solving process related to the K.2.2 coded participant, it can be said that he recalled former knowledge related to the problem firstly, then continued according to a plan he prepared, reached the result with continual checking and checked the result if it was correct or not. As it is stated in Figure 5, the participant, at this stage, demonstrated totally 10 behaviours as; within the scope of awareness 2 , evaluation 3 , regulation 2 and cognitive behaviour 3 . The description of K.2.2 coded participant related to the general problem-solving process was as follows;

Table 11. The solving process of K.3.1 coded participant

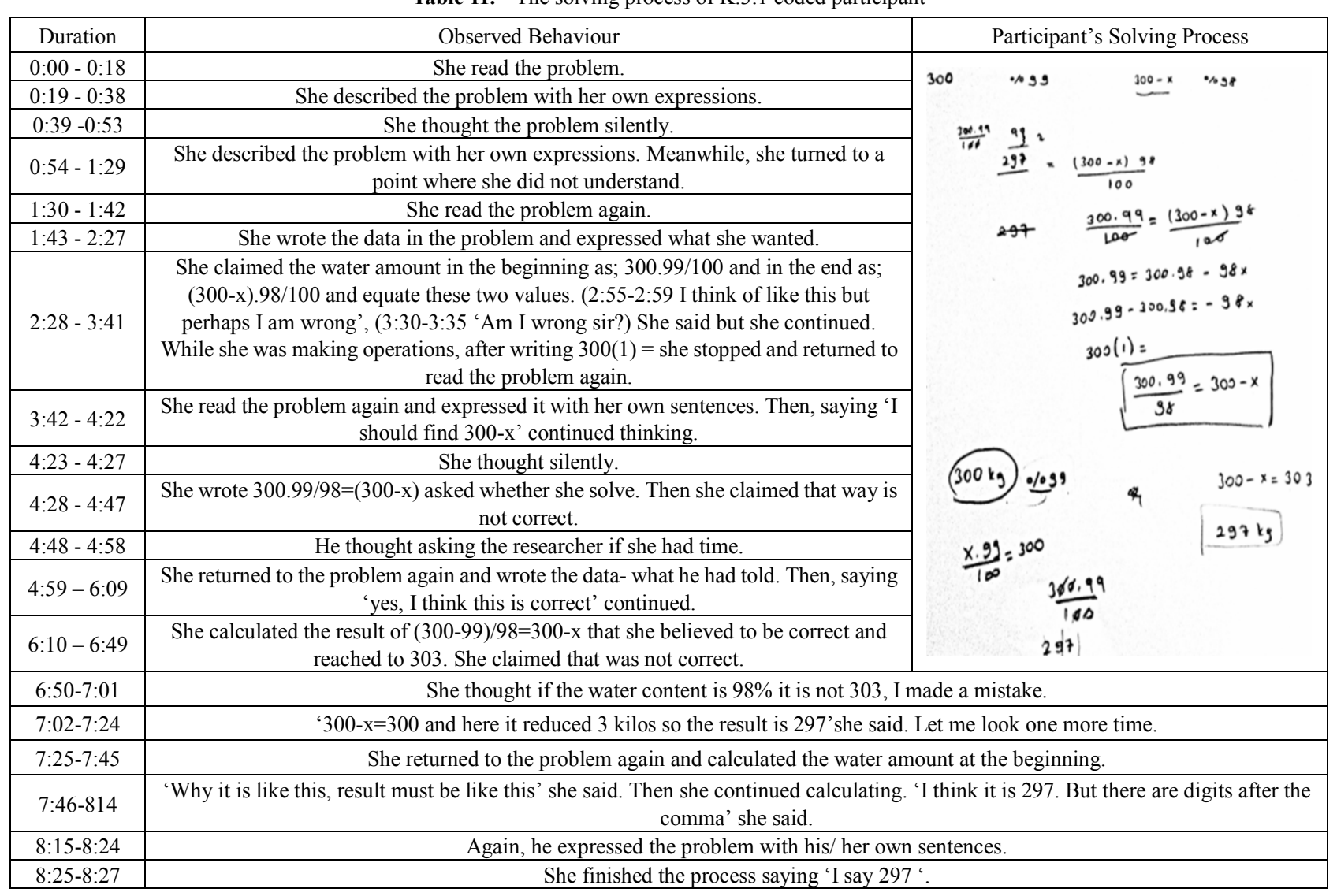

'Firstly I try to understand the problem. If I can't, I cool down from the problem. I take notes of the data and determine the beneficial items. Then I determine what it want and make plan according to the solution. Generally, I have the confidence of my solutions. I only check my operations'

When the expression of K.2.2 coded participant about the problem-solving process in general compared with behaviours he demonstrated during problem-solving process, it was coded as substantially coinciding. Because, when the description of the participant on general problem-solving process compared with her behaviours on this problem, it shows differences in terms of checking the results. Actually, the participant had checked the solution during the solving process but, because of his confidence, he did not check the final result. The participant demonstrated a few number of metacognitive behaviours and reached to correct result at the end of the process. Moreover, after the interview, the participant claimed that they grew up watermelons with her family in summer and usually came across the situations defined in the problem.

\section{- The Solving Process of K.3.1 Coded Participant}

K.3.1 coded participant finished the solving process in 8 minutes 27 seconds and could not solve the problem correctly. The solution and behaviours during the process were shown in Table 11. 
The sequence of action cards of K.3.1 coded participant showing the solving process was shown below;

\begin{tabular}{|c|c|c|}
\hline \multicolumn{3}{|r|}{ BEGINNING } \\
\hline v & (E) & I thought 'I can't do it'. \\
\hline 5 & (A) & $\begin{array}{l}\text { I tried to remember if I had ever done a problem like this } \\
\text { before. }\end{array}$ \\
\hline$\checkmark$ & (A) & $\begin{array}{l}\text { I thought about something I had done another time that } \\
\text { had been helpful. }\end{array}$ \\
\hline v & (C) & I thought about what the problem requires \\
\hline & (A) & I thought about what I already know. \\
\hline & (R) & I made a plan to work it out. \\
\hline$\checkmark$ & (R) & I thought about what I would do next. \\
\hline$v$ & (C) & I made a proportion. \\
\hline$v$ & (E) & I thought about how I was going \\
\hline$v$ & (E) & I thought 'Is this right?'. \\
\hline$v$ & (R) & I thought about a different way to solve the problem. \\
\hline$v$ & (R) & I changed the way I was working. \\
\hline$v$ & (R) & I made a plan to work it out. \\
\hline$\checkmark$ & (A) & I thought 'I know what to do'. \\
\hline$v$ & (E) & I checked my work. \\
\hline & & SOLUTION \\
\hline
\end{tabular}

Figure 6. The sequence of action cards of K.3.1

As it is stated in Table 11, the analysis of the solving process related to the K.3.1 coded participant showed that she started the process with thinking of she cannot solve the problem. The participant evaluated her former knowledge about the problem, tried to solve it through a way she determined, then changed her way, used second way and completed the process. As it is stated in Figure 6, participant, in the process, demonstrated totally 15 behaviours as; within the scope of awareness 4, evaluation 4, regulation 5 and cognitive behaviours 2. The description of K.3.1 coded participant related to general problem-solving process was as follows;

'When I saw the problem first, I thought I could not solve it. I did not have much confidence. In general, I start solving thinking that I can solve the problem. The steps are always the same.'

When the expression of K.3.1 coded participant about the problem-solving process was compared with behaviours which she demonstrated during problem-solving process, it was coded as substantially coinciding. Although she generally started with the views that she could solve the problem, she demonstrated completely different behaviours. The participant read the question again even at the end of the process. Before checking the latest result, she claimed that she finished the process.

\section{- $\quad$ The Solving Process of K.3.2 Coded Participant}

K.3.2 coded participant tried to solve the problem in 7 minutes 40 seconds, and she finished the process expressing she could not solve it. Her struggles and behaviours related to her solving process were demonstrated in Table 12.

Table 12. The solving process of K.3.2 coded participant

\begin{tabular}{|c|c|c|}
\hline Duration & Observed Behaviour & Participant's Solving Process \\
\hline $0: 00-0: 19$ & She read the problem. & \multirow{9}{*}{$\begin{array}{l}300 \frac{99}{105}=297 \mathrm{~kg} \text { su } \\
(300-x) \cdot \frac{98}{102} \\
\text { 'su' means 'water' } \\
\text { at first.' and calculated the water amount as } 297 \mathrm{~kg} . \\
\text { ng 'Decreases to 98\%, water amount', 'if, at the beginning } \\
\text { decreases'. } \\
\text { he wrote. But she could not continue the problem. } \\
\text { ns as; at 3:57 'A very complicated problem, Sir. Is there } \\
\text { 5:37 'I can't solve it. Because I remember nothing'. At the } \\
\text { I I can't solve it, is better to give up'. }\end{array}$} \\
\hline $0: 20-0: 54$ & $\begin{array}{l}\text { She expressed the problem with her own expression and tried to } \\
\text { understand the problem. }\end{array}$ & \\
\hline $0: 55-1: 53$ & She thought silently looking at the problem. & \\
\hline $1: 54-2: 02$ & She expressed the problem with her own expression again. & \\
\hline 2:03-2:13 & She thought silently looking at the problem. & \\
\hline $2: 14-2: 40$ & She started to solve saying 'I have to find out the water amount at first.' and calculated the water amount as $297 \mathrm{~kg}$. & \\
\hline $2: 41-3: 33$ & $\begin{array}{l}\text { She thought silently looking at the problem what she understood humming 'Decreases to } 98 \% \text {, water amount', 'if, at the beginning } \\
\text { is } 300 \text { then water amount decreases'. }\end{array}$ & \\
\hline $3: 34-3: 45$ & If the weight decreases as; $\mathrm{x}(300-\mathrm{x}) .98 / 100$ will be the water she wrote. But she could not continue the problem. & \\
\hline $3: 46-7: 40$ & $\begin{array}{l}\text { She thought silently looking at the problem. She used some expressions as; at 3:57 'A very complicated problem, Sir. Is there } \\
\text { another person who solved this before?' at 4:59 'I have no idea, sir' at 6:37 'I can't solve it. Because I remember nothing'. At the } \\
\text { end of the period she finished the process saying 'I can't solve it, is better to give up'. }\end{array}$ & \\
\hline
\end{tabular}


The sequence of action cards of K.3.1 coded participant showing the solving process was shown below;

\begin{tabular}{|c|c|c|}
\hline \multicolumn{3}{|r|}{ BEGINNING } \\
\hline$\sqrt{2}$ & (A) & $\begin{array}{c}\text { I tried to remember if I had ever done a problem like this } \\
\text { before. }\end{array}$ \\
\hline 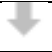 & (R) & I thought about what I would do next. \\
\hline 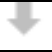 & (E) & I thought about whether what I was doing was working. \\
\hline 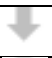 & (R) & I thought about a different way to solve the problem. \\
\hline 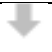 & (E) & I thought 'I can't do it'. \\
\hline \multicolumn{3}{|r|}{ ABANDONED BEFORE REACHING THE SOLUTION } \\
\hline
\end{tabular}

Figure 7. The sequence of action cards of K.3.2

As it is stated in Table 12, from the analysis of the solving process related to the K.3.2 coded participant, it can be said that she tried to solve the problem with resembling it to a problem which was formerly solved by him. During the process, as he said 'I don't think aloud during problem-solving cause I am confused then' he did not express a part of the process. As it is stated in Figure 7, participant, in the process, demonstrated totally 5 behaviours as; within the scope of awareness 1 , evaluation 2 and regulation 2. The description of K.3.2 coded participant related to general problem solving process was as follows;

'First of all, I think about if I have knowledge about the problem I met. Then, considering the solution, I make plans about the solutions. I continue according to the plan I made try to reach at the solution. At the point I stuck or think that I make mistake, I turn back to beginning and try a different way.'

It was determined that though the behaviours of K.3.2 coded participant and the beginning of her descriptions were related to general solving process entirely coinciding, she could not make a plan to continue the solution, the rest of her solution could not be observed. Although the participant used 7 minutes 40 seconds, it was remarkable that she did nothing to solve it.

\section{- $\quad$ The Solving Process of K.4.1 Coded Participant}

K.4.1 coded participant finished the solving process in 13 minutes 10 seconds and could solve the problem correctly. The solution and behaviours during the process were shown in Table 13.

Table 13. The solving process of K.4.1 coded participant

\begin{tabular}{|c|c|c|}
\hline Duration & Observed Behaviour & Participant's Solving Process \\
\hline $0: 00-0: 27$ & She read the problem. & \multirow{18}{*}{ 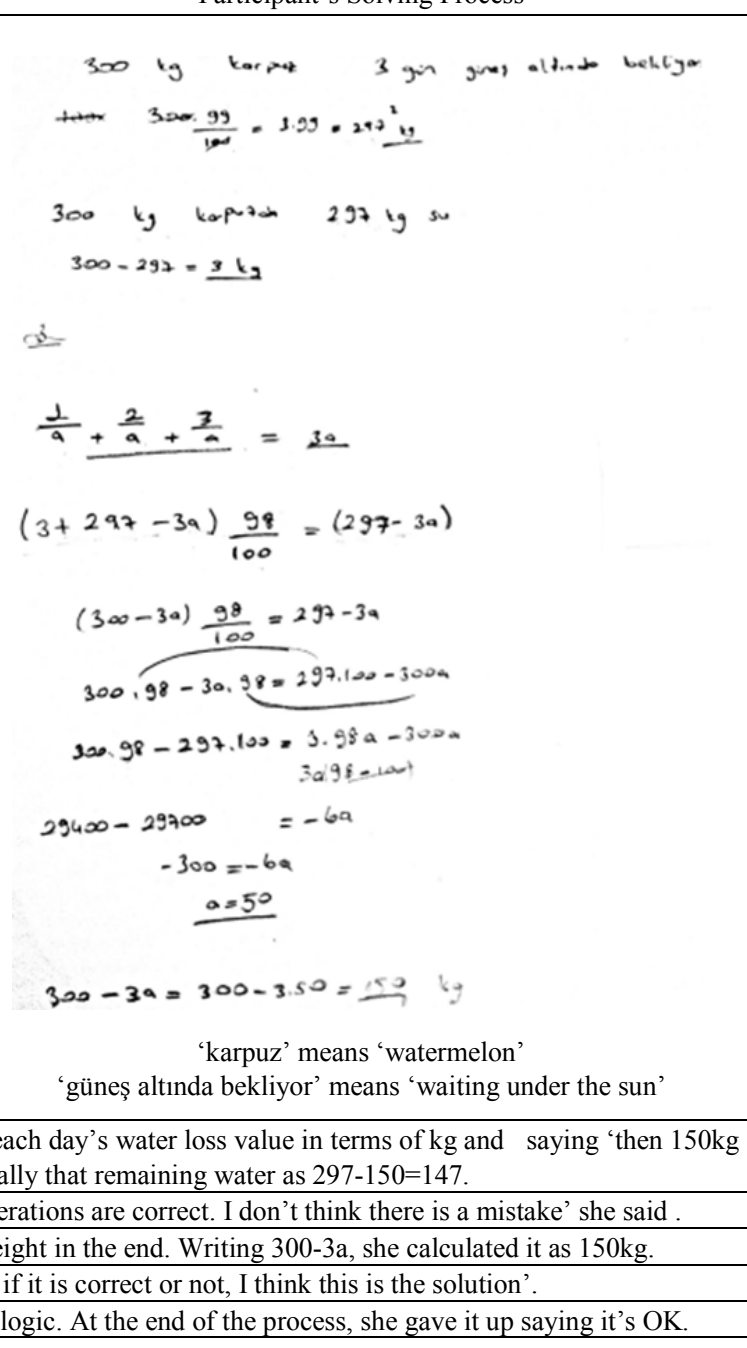 } \\
\hline $0: 28-0: 39$ & She thought silently looking at the problem. & \\
\hline 0:40-1:06 & She read the problem again. & \\
\hline $1.07-2: 09$ & $\begin{array}{c}\text { She expresses the data in the problem. Thinking of } \\
\text { watermelon, she expressed that it has solid and liquid } \\
\text { sides and that is; weight loss can only be originated in } \\
\text { liquid side. }\end{array}$ & \\
\hline $2: 10-2: 36$ & She summarized writing the data in the problem. & \\
\hline $2: 37-3: 46$ & $\begin{array}{l}\text { She wrote } 100 \mathrm{x} \text { and thought for a while humming 'If I } \\
\text { express the water amount in the watermelon as } 100 x \text {. I } \\
\text { write nothing for the solid amount. Because it does not } \\
\text { change'. }\end{array}$ & \\
\hline $3: 47-4: 40$ & $\begin{array}{l}\text { She stroke 100x out and calculated solid and liquid } \\
\text { weight of watermelons. }\end{array}$ & \\
\hline $4: 41-4: 52$ & She returned and read the problem again. & \\
\hline $4: 53-6: 11$ & $\begin{array}{l}\text { She expressed the data in the problem and what she } \\
\text { wanted to do. Then she made reasoning. She thought if } \\
\text { three days' temperature and the water loss were equal. In } \\
\text { the end, she started solving claiming 'I assume the } \\
\text { temperature in each day was equal'. }\end{array}$ & \\
\hline & She claimed 'during this period, assuming each day as a, & \\
\hline $6: 12-7: 21$ & $\begin{array}{l}\text { water reduces as } 3 \mathrm{a} \text { and watermelons weight will be } \\
(3+297-3 \mathrm{a}) \text { and } 98 / 100 \text { of it is equal to (297-3a).' }\end{array}$ & \\
\hline $7: 22-8: 39$ & She described what she wrote to the researcher. & \\
\hline $8: 40-10: 33$ & $\begin{array}{c}\text { She found a value solving the equation } \\
(3+297-30) \cdot 98 / 100=(297-3 a) . \text { (She asked herself if she } \\
\text { would cross-multiplication at } 8: 54 \text {. }\end{array}$ & \\
\hline 10:34-11:09 & $\begin{array}{l}\text { She thought about the value she found. She expressed it was each day's water loss value in terms of kg and saying 'then } 150 \mathrm{~kg} \\
\text { water evaporates' she expressed verbally that remaining water as } 297-150=147 \text {. }\end{array}$ & \\
\hline $11: 10-11: 25$ & \multirow{2}{*}{$\begin{array}{l}\text { She thought silent. ' } 147 \text { kilos. It is too much. But my operations are correct. I don't think there is a mistake' she said . } \\
\text { She turned to the problem and said 'I must find the weight in the end. Writing } 300-3 \text { a she calculated it as } 150 \mathrm{~kg}\end{array}$} & \\
\hline 11:26-11:51 & & \\
\hline $11: 52-11: 59$ & $\begin{array}{l}\text { She turned to the problem and said 'I must find the weight in the end. Writing } 300-3 \mathrm{a} \text {, she calculated it as } 150 \mathrm{~kg} \text {. } \\
\text { She thought silently and said 'I don't know if it is correct or not, I think this is the solution'. }\end{array}$ & \\
\hline 12:00-13:10 & Saying 'To look again' she reviewed the stages and their logic. At the end of the process, she gave it up saying it's OK. & \\
\hline
\end{tabular}


The sequence of action cards of K.4.1 coded participant showing the solving process was shown below;

\begin{tabular}{|c|c|c|}
\hline \multicolumn{3}{|r|}{ BEGINNING } \\
\hline 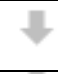 & (A) & $\begin{array}{l}\text { I tried to remember if I had ever done a problem like this } \\
\text { before. }\end{array}$ \\
\hline$\checkmark$ & (A) & I thought 'I know this sort of problem' \\
\hline 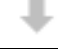 & (R) & I thought about what I would do next. \\
\hline 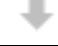 & (A) & I thought about what I already know. \\
\hline 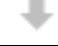 & (A) & I thought 'I know what to do'. \\
\hline 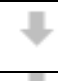 & (C) & $\begin{array}{l}\text { I thought of the form of water melon and weight } \\
\text { difference might be originated with water loss. }\end{array}$ \\
\hline 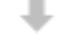 & (A) & I thought 'I know what to do'. \\
\hline 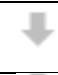 & (A) & $\begin{array}{l}\text { I thought about something I had done another time that } \\
\text { had been helpful. }\end{array}$ \\
\hline 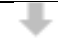 & (R) & I made a plan to work it out. \\
\hline$\checkmark$ & (C) & I made operations. \\
\hline 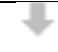 & (E) & I thought about how I was going. \\
\hline$\checkmark$ & (E) & I checked my work. \\
\hline 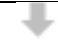 & (E) & I thought about whether what I was doing was working. \\
\hline 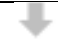 & (E) & I checked my work. \\
\hline 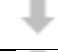 & (C) & I continued with my operations. \\
\hline$\nabla$ & (E) & I thought 'Is this right?' \\
\hline 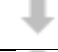 & (E) & I checked my work. \\
\hline 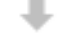 & (E) & I thought 'Is this right? \\
\hline & & SOLUTION \\
\hline
\end{tabular}

Figure 8. The sequence of action cards of K.4.1

As it is stated in Table 13, the analysis of the solving process related to the K.4.1 coded participant indicated that she recalled a similar problem she had solved before and regarded a statement which would help her to solve this one, checked her former knowledge relevant to the problem and then continued according to her plan, reached to the solution checking the process once- the operations several times and the solution if it was correct or not. As it is stated in Figure 8, the participant demonstrated totally 18 behaviours as follows; within the scope of awareness 6 , evaluation 7 , regulation 2 and cognitive behaviour 3. The description of K.4.1 coded participant related to the problem-solving process was as follows;

'In order to solve a mathematical problem, firstly, I try to understand the data given in the problem. Then, according to these data, I thought about a correct way. After determining my procedure, I try to reach the solution with the current data. In the end, I do evaluation checking my solutions.'

When the expression of K.4.1 coded participant on the problem-solving process was compared with behaviours which she demonstrated during problem-solving process, it was coded as entirely coinciding. The participant used half of her time to understand the problem; she made a plan, continually checked the application process of the plan and evaluated the result she reached. Moreover, the problem-solving process of the participant has a statement including no turning back among the metacognitive behaviours. The participant started the process with behaviours of awareness, applied regulation and then evaluation. Then she demonstrated no turning back.

- $\quad$ The Solving Process of K.4.2 Coded Participant

K.4.2 coded participant finished her process in 13 minutes 30 seconds and solved the problem correctly. Her solution and behaviours she demonstrated were shown in Table 14. 
Table 14. The solving process of K. 4.2 coded participant

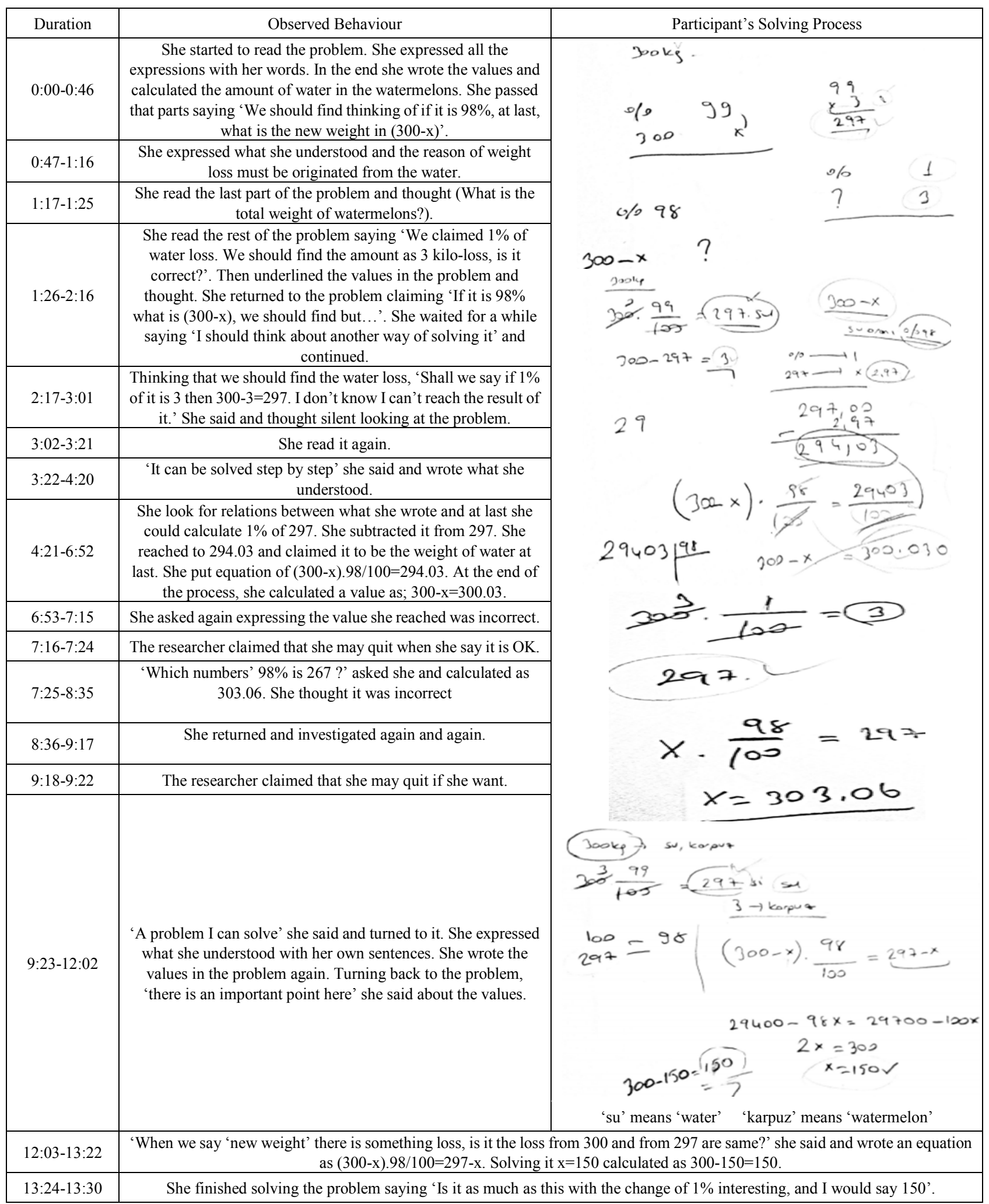


The sequence of action cards of K.4.2 coded participant showing the solving process was shown below;

\begin{tabular}{|c|c|c|}
\hline \multicolumn{3}{|r|}{ BEGINNIG } \\
\hline 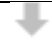 & (R) & I thought about what I would do next. \\
\hline 8 & (C) & $\begin{array}{l}\text { I calculated solid and liquid weight according to the } \\
\text { values. }\end{array}$ \\
\hline 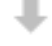 & (E) & I thought about how I was going. \\
\hline$\nabla$ & $(\mathrm{R})$ & I thought about a different way to solve the problem. \\
\hline 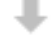 & (E) & I thought 'I can't do it'. \\
\hline 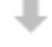 & $(\mathrm{R})$ & I thought about a different way to solve the problem. \\
\hline 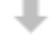 & (R) & I changed the way I was working. \\
\hline 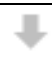 & (C) & $\begin{array}{l}\text { I calculated solid and liquid amount again. I set a new } \\
\text { proportion. }\end{array}$ \\
\hline$v$ & (E) & I thought 'Is this right?'. \\
\hline 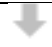 & (E) & I checked my work. \\
\hline 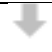 & $(\mathrm{R})$ & I thought about a different way to solve the problem. \\
\hline 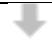 & $(\mathrm{R})$ & I changed the way I was working. \\
\hline$\nabla$ & (C) & I calculated water amount again. I set a new proportion. \\
\hline 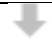 & (E) & I thought 'Is this right?'. \\
\hline$\nabla$ & (E) & I checked my work. \\
\hline 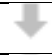 & $(\mathrm{R})$ & I thought about a different way to solve the problem. \\
\hline$v$ & (R) & I changed the way I was working. \\
\hline 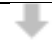 & (C) & I set a new proportion. \\
\hline 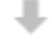 & (E) & I thought 'Is this right?'. \\
\hline & & SOLUTION \\
\hline
\end{tabular}

Figure 9. The sequence of action cards of K.4.2

As it is stated in Table 14, after analysing the solving process related to the K.4.2 coded participant, she passed to the solution without a plan after trying to understand the problem, and she continued with other ways because of her incorrect solutions. With her fourth try, she reached the correct answer and finished the process. As it is shown in Figure 9, the participant demonstrated totally 19 behaviours as follow; within the scope of awareness 0 , evaluation 7 , regulation 8 and cognitive behaviours 4 . The description of K.4.2 coded participant related to the general problem-solving follows;

'In similar problems, I try to find a solution to the problem glancing it in general. With the direction of numerical data, I try some results. If I encounter with an incorrect solution, I think of any operational mistakes, then I think about logical errors in my equation. I try to reach the correct solution'

When the expression of K.4.2 coded participant on problem solving process in general compared with behaviours she demonstrated during problem solving process, it was coded as entirely coinciding. The participant, in the process, did not demonstrate any awareness and could not keep the process with a determined plan.

At this stage of the findings, the metacognitive behaviours of the participants in the process of problem solving were analysed considering the class level. Frequency values of demonstrated metacognitive behaviours according to the class level were shown in Figure 11.

As it is shown in Figure 11, considering the number of demonstrated metacognitive behaviours by the participants; for 1 st class: 25 (aw: 7, ev: 12, reg: 6), for 2nd class: 8 (aw: 6, ev: 8, reg: 4), for 3rd class: 18 (aw: 5, ev: 6, reg: 7) and for 4th class: 30 (aw: 6, ev: 14, reg: 10) were determined. Within the light of total frequencies, participants, mostly demonstrated metacognitive behaviours within the scope of evaluation $(\mathrm{f}=40)$ during the solving process. With this aspect, mostly used behaviours were; 'I checked my work' ( $\mathrm{f}=11)$ and 'I thought is this right?' ( $\mathrm{f}=10)$. Secondly used behaviours were those within regulation $(\mathrm{f}=27)$. Mostly used behaviours within this scope were; 'I thought about a different way to solve the problem' ( $\mathrm{f}=9$ ) and 'I thought about what I would do next' $(\mathrm{f}=7)$. It was determined that participants used behaviours within the scope of awareness at least $(\mathrm{f}=24)$. Mostly used behaviours within this scope were; 'I tried to remember if I had ever done a problem like this before' $(\mathrm{f}=6)$ and I thought 'I know what to do' $(\mathrm{f}=6)$.
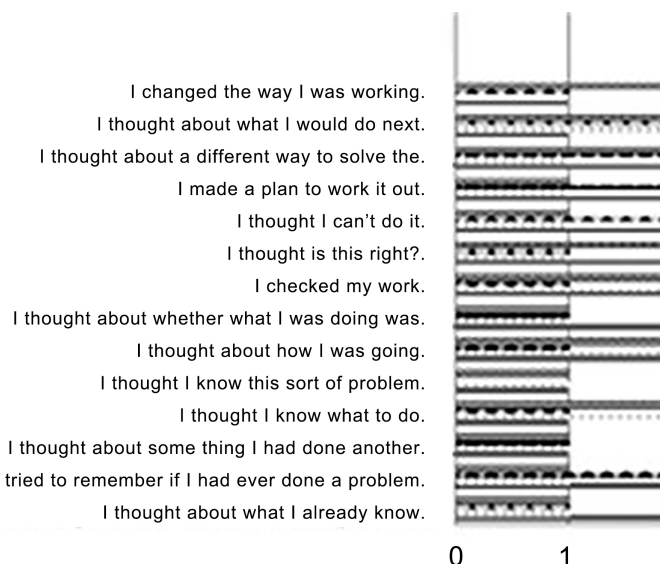

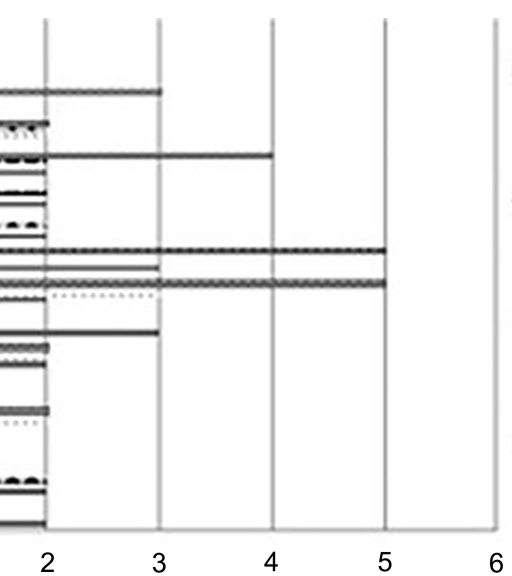

m 4th Class

3th Class

2nd Class

* 1st Class

Figure 10. The distribution of demonstrated metacognitive behaviours according to class level. 

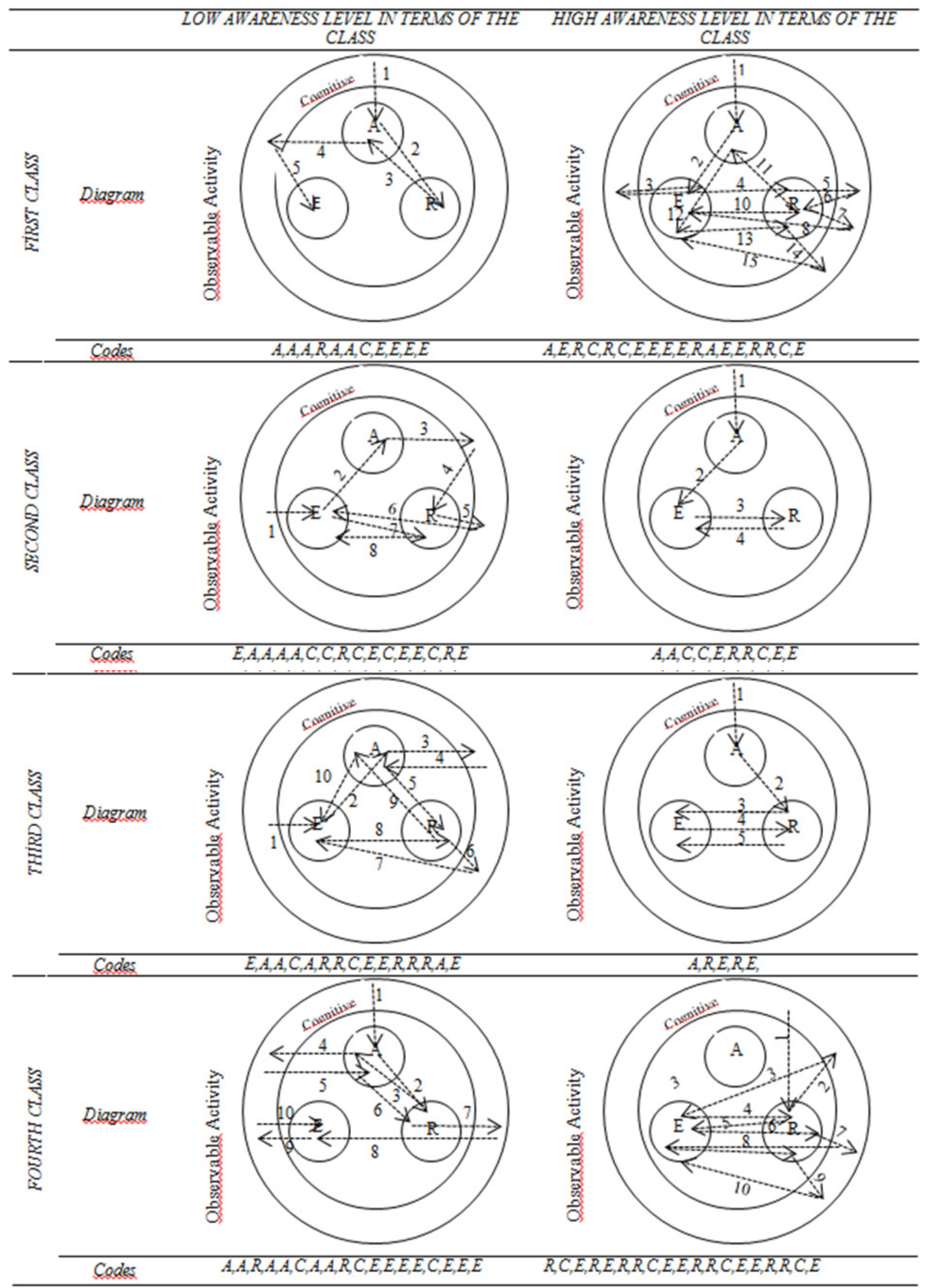

Figure 11. The problem solving processes of the participants

The participants' expressions were related to general problem solving coincided with their process during the research. Therefore, metacognitive behaviours demonstrated by the participants were shown in the diagrams. In the diagrams, A means awareness; E means evaluation, and $\mathrm{R}$ means regulation. Assuming all of the participants stated the solving process with reading the problem, and that is a cognitive behaviour, all of the diagrams started with C. All the behaviours under the same headline were shown with an arrow. For instance; the complete sequence belonging to 
K.1.1 coded participant, A, A, A, R, A, A, C, E, E, E, E, there were five arrows, used for each one as; from $\mathrm{C}$ to $\mathrm{A}$, from $A$ to $\mathrm{R}$, from $\mathrm{R}$ to $\mathrm{A}$, from $\mathrm{A}$ to $\mathrm{C}$, from $\mathrm{C}$ to $\mathrm{E}$. In order to determine the sequence of behaviours, sequence numbers were written on the arrows. The activity sequence on the basis of diagrams was indicated in the code parts under the diagrams.

The Figure 12 said that K.1.2, K.2.2 and K.3.2 coded participants started the process within the scope of awareness. Yet, K.4.2 coded participant with high score of awareness started the process with behaviours within the scope of regulation but no behaviours of awareness. K.2.1 and K.3.1 coded participants with the lowest scores started the process thinking that they cannot solve the problem within the scope of evaluation. Yet, also, K.1.1 and K.4.1 coded participants with low score started the process considering their awareness related to the problem within the scope of awareness as K.1.2, K.2.2 and K.3.2. In general, analysing the processes, no definite behaviours were encountered in terms of behaviour sequence among the participants who had the highest and the lowest awareness scores. However, a great number of participants especially those with high metacognitive awareness started the process associating the problem others they recalled within the scope of awareness. Considering the behaviour sequence that the participants demonstrated during the solving process, no differences or pattern were encountered in class level.

As all of the data obtained during the research within the scope of first and second sub-problem were evaluated as a whole, the findings can be summarised as follows.

It was observed that there is a relation between the participants' MAI scores and their metacognitive behaviours during the process of problem solving. Moreover, it was noticed that high metacognitive awareness level is significant for problem solving process in terms of reaching the correct results and not reaching incorrect results. Therefore, the K.1.1 coded participant- first class, with low score- solved the problem through his first way and checked the result. In addition, although the K1.2 coded

participant, who is at the same class and has high awareness score, found the same result with K.1.1checked the result continuously and thought on it 18 times more, gave it up saying she will not find the result. Similarly, K.2.1 and K.3.1 coded participants with low awareness scores, demonstrated some of the behaviours during the process unconsciously and found incorrect result in the end. K.2.2 coded participant with high awareness score, recalled her previous knowledge about the problem, continued solving it with a plan she made and found correct result checking it continuously. The K.3.2 coded participant thought the problem about 8 minutes, considered her knowledge about it, did not make any plan and abandoned the process without continuing with relevant operations. Yet, the K.4.1 coded participant, in fourth class with low score, solved the problem correctly and demonstrated metacognitive behaviours frequently. The K.4.2 coded participant with high awareness score, though she could not continue the process through a plan, and continually checked the operations and finally reached the correct result.

Considering the fact that the participants from fourth class solving the problem correctly and the data in the Figure 11, they were observed to have more success in problem solving and more frequent metacognitive behaviours that they demonstrated in solving process compared with the participants of other classes.

No relation was observed between using metacognitive behaviours and problem solving achievement. For instance, K.2.1 coded participant demonstrated almost twice more metacognitive behaviour than K.2.2 coded participant at the same class but as K.2.1 solved the problem incorrectly K.2.2 solved it correctly. Moreover, K.4.1 coded participant demonstrated over twice more metacognitive behaviours than K.2.2 and both of them could solve the problem correctly.

During the process, it was observed that individuals sometimes planned to demonstrate metacognitive behaviours but as they gave different meanings to them which they could not. For instance; K.1.1 and K.3.1 coded participants who gave wrong answers, claimed that they checked their results but it was noticed that they focused on the operation process rather than their results. Furthermore, sometimes, it was observed that participants demonstrated metacognitive behaviours unconsciously. Although K.2.1 coded participant expressed that he did not check his results because of a previous experience, in the process he declared an incorrect operation by checking.

Considering with a more general aspect, 2 of the 8 participants gave up the problem solving claiming that they cannot reach any solutions. 3 of the rest 6 participants gave correct and 3 of them incorrect answers. Analysing the solving process of 2 participants giving correct answers, while K.2.2 coded participant followed a simple process within her plan, K.4.1 coded participant followed a similar way, too. K.4.2 coded participant tried to reach the result with various operations rather than following a plan she made. This statement represented objective side of problem solving process. When K.2.2 and K.4.1 coded participants' ways were analysed, it was seen that they resembled mainly and each participant checked their knowledge and made a plan checked their processes and results.

\section{Conclusion and Discussion}

The metacognitive awareness of secondary pre-service mathematics teachers was investigated on the basis of class level and gender. In addition, an analysis was carried out related to the metacognitive behaviours of pre-service secondary mathematics teachers during solving process of non-routine problem. The results showed that the metacognitive awareness of pre- service secondary school mathematics teachers was determined as medium and high. It was also determined that their relevant awareness did not differ in terms of the variables of class level and gender. On 
account of the determined problem, it was noticed that the participants demonstrated the metacognitive behaviours within the scope of evaluation most, awareness at least level. The numbers of metacognitive behaviours demonstrated by the fourth class in comparison, to the other class levels, were high. However, there was no difference or pattern in terms of the behaviour sequence. The results were shown below as comparative and detailed.

In general sense, it was noticed that almost half of the pre-service secondary school mathematics teachers had medium metacognitive awareness level and the rest half had high. Similarly Jaafar and Ayub [57] referred that a great number of university students who were in different departments and had taken the analysis lesson, had high level of awareness and a very few number of them were in low level.

It was realised that these metacognitive awareness among pre-service secondary school mathematics teachers did not demonstrate any differences in terms of class level, gender and with the interaction of these two variables. Panaoura, Philippou and Christou [9] in their research on 4th, 5th and 6th graders and even in the survey they used in this research, noticed that there was no difference in the students' thoughts about their metacognitive behaviours in terms of the class level., Stewart, Cooper and Moulding[46] claimed that gender is not an effective variable on metacognitive awareness. The finding about the gender was in parallel with claim

Considering the number of metacognitive behaviours demonstrated by the participants during the problem-solving process, the most common metacognitive behaviours categories occurred in terms of the class levels orderly are: in first class; evaluation, awareness, regulation; in second class; evaluation, awareness, regulation; in third class; regulation, evaluation, awareness; at the fourth class; evaluation, regulation, awareness. As it is evaluated in terms of all participants, the most observed behaviour categories are evaluation most and awareness at least. Within the scope of evaluation; 'I checked my work.'-' I thought 'Is this right?' within the scope of regulation; 'I thought about a different way to solve the problem.' -' I thought about what I would do next' and in awareness 'I tried to remember if I had ever done a problem like this before' -' I thought 'I know what to do' were mostly used statements. The result in which the least used behaviours within the scope of awareness in the problem-solving process represented similarities with the researches by Wilson and Clarke [33] and Wong[47] in each class level.

Although there is a difference in terms of the number of demonstrated metacognitive behaviours among class levels, in the sequence of metacognitive behaviours which the participants demonstrated during the problem-solving process, there is not any difference in terms of awareness score and class level. In addition, it can be claimed that participants started the solving process with trying to associate the problem with others they had solved before in the awareness process. In addition, it was realised that they started with behaviours within the scope of evaluation and regulation. With a general aspect, mutual transitions among awareness, evaluation and regulation were common and the process, sometimes, completed with no turning back, and sometimes all the behaviours in this process was not demonstrated at all. Another significant point is; as in the example in which the participant stated that he grew up watermelons with his family in summer and encountered the situations as in the problem frequently, individuals experiences related to the problem statement, having the awareness level much may contribute to their problem-solving process. Similarly, in their study on 6th grade, Wilson and Clarke [33] reported similar results; for instance, he expressed that when they encountered with difficulties, they turned back to awareness. Even Yimer and Ellerton [10] in their studies with pre-service teachers said that individuals' problem-solving plans were not occurred immediately, therefore they dealt with the problem in different ways and returned several times.

It can be claimed that effective usage of metacognitive behaviours in the problem-solving process have a close relation with metacognitive awareness level. It was noticed that having high metacognitive awareness level was significant in terms of reaching correct results or not reaching incorrect results in the problem-solving process. This situation was originated from the effects of metacognitive behaviours in the problem-solving process. The metacognition skills of students have a direct effect on the problem-solving achievement [49]. Those who have these skills can check and follow the solving processes, interrogate logically and make arrangements if necessary $[9,28,30]$.

From the fact that they solved the problem correctly and the number of their metacognitive behaviours during the problem-solving process, it can be said that the participants from fourth class are more successful in the problem-solving process and demonstrate metacognitive behaviours frequently (see Table 13-14, Figure 10-11). It was noticed that especially among the participants from the fourth class, metacognitive behaviours are more effective and they have skills to direct the process with them. As it was stated by Panaoura, Philippou and Christou[9] and Stewart, Cooper and Moulding[46], it can be expressed that the difference is originated from the participants' ages and cognitive forms related to it and their developed relations with mathematics.

It can also be claimed that demonstrating metacognitive behaviours more during the problem-solving process does not mean to ensure the success of solution or demonstrating it less affect the problem-solving success negatively. Similarly, in the research, Wilson and Clarke[33] stated that frequent use of metacognitive skills does not mean they are successful in problem-solving. Yet, this result should never be considered as there is no relation between metacognitive behaviours and problem-solving success. Because much research showed that the students demonstrating metacognitive behaviours frequently are more successful in the problem-solving $[9,11,27,29,53]$. One of the possible 
reasons of this contrary situation as it was stated by Panaoura, Philippou and Christou[9], Garofalo and Lester[31], it is a complex interplay between cognition and metacognition. Therefore, considering the observations, students may not have enough cognitive skills to respond metacognitive behaviours.

The reasons of disproving metacognitive behaviours were observed in two ways. One of them was deficient-incorrect understanding of metacognitive behaviours. Analysing the process, it can be observed that though some of the participants thought that they had checked the results, this check was not more than correctness of operations. The second reason of disproving metacognitive behaviours was that they did not want to demonstrate it deliberately. Checking the results, a statement like this was encountered during the research. One of the participants expressed a former experience, other claimed self-confidence as a reason. In the research by Pugalee[16] on high school students, expressed that participants did not allow time to check the results. In addition, it was noticed that some of the participants showed relevant behaviours in the problem-solving process. With the definition of Ericsson and Simon[35], McKoon and Ratcliff[22], this statement can be originated from automatized metacognitive behaviours and individuals' being unaware of this.

Accepting a general aspect, 2 out of 8 participants gave up the problem-solving claiming that they cannot reach any solutions. 3 of the rest 6 participants gave correct and 3 of them incorrect answers. Analysing the process of two participants giving correct answers, it can be claimed that both of them checked their previous knowledge related to the problem, made a plan, checked process and results. This statement is entirely coinciding with successful solving behaviours defined by Schoenfeld[6,7]. Although the other participant continued without a definite plan, it was observed that she checked the process continuously. It was noticed that those who gave incorrect answers did not check the results but checked their operations. Moreover, the operations were carried out being unaware of the process. As Artzt and Armour-Thomas[4] claimed, the difficulties originates from disarranging the process correctly. Yet, it is crucial to consider possible differences during the process.

Within the light of the results, following suggestions can be given:

- Individual's cognitive skills are important for metacognitive behaviours directing and evaluating the problem-solving process. Thus, it is also crucial to raise awareness of individuals' behaviours within the scope of awareness and this may contribute to increasing their success in the problem-solving process.

- Because of the deficient-incorrect understanding of participants on metacognitive behaviours, (meanings as checking the results and operations), the participants cannot demonstrate the relevant behaviours during the problem-solving process in the study. Therefore, much research on putting correct meanings to metacognitive behaviours is needed in the field.
- As the results of the research are directly related to the study group and the applied problem, similar research with different study groups and different problems may contribute to the field.

\section{REFERENCES}

[1] A. Adibnia, I. J. Putt. Teaching problem solving to year 6 students: A new approach, Mathematics Education Research Journal, Vol.10, No.3, 42-58. 1998.

[2] A. Akın, R. Abacı, B. Çetin. The validity and reliability of the Turkish version of the metacognitive awareness inventory, Educational Sciences: Theory \& Practice, Vol.7, No.2, 671-678. 2007.

[3] A. Desoete, H. Roeyers, A. De Clercq, Can offline metacognition enhance mathematical problem solving?, Journal of Educational Psychology, Vol.95, No.1, 188-200. 2003.

[4] A. F. Artzt, E. Armour-Thomas. Development of a cognitive-metacognitive framework for protocol analysis of mathematical problem solving in small groups, Cognition and Instruction, Vol.9, No.2, 137-175. 1992.

[5] A. H. Schoenfeld. Episodes and executive decisions in mathematical problem solving. In R. Lesh \& M. Landau (Eds.), Acquisition of mathematics concepts and processes, (pp. 345-395). Academic Press, New York, 1983.

[6] A. H. Schoenfeld. Learning to think mathematically: Problem solving, metacognition, and sense making in mathematics, In D. A. Grows (Ed.), Handbook of research on mathematics teaching and learning (pp. 334-370), New York: Macmillan, 1992.

[7] A. H. Schoenfeld. Problem solving from cradle to grave, Annales de Didactique et de Sciences Cognitives, No.11, 41-73. 2006.

[8] A. L. Brown. Knowing when, where and how to remember: A problem of metacognition. In R. Glaser (Ed.), Advances in instructional psychology (pp. 77-165), NJ: Erlbaum, Hillsdale, 1978.

[9] A. Panaoura, G. Philippou, C. Christou. Young pupils' metacognitive ability in mathematics. Paper presented at CERME 3: Third Conference of the European Society for Research in Mathematics Education. Online available from http://www.dm.unipi.it/ didattica/CERME3/proceedings/Gr oups/TG3/TG3_Panaoura_cerme3.pdf, 2003.

[10] A. Yimer, N. F. Ellerton. A five-phase model for mathematical problem solving: Identifying synergies in pre-service-teachers' metacognitive and cognitive actions, ZDM Mathematics Education, Vol.42, No.2, 245-261. (2010).

[11] A. Yimer, N. F. Ellerton. Cognitive and metacognitive aspects of mathematical problem solving: An emerging model. In P. Grootenboer, R. Zevenbergen, \& M. Chinnappan (Eds.), Identities, cultures, and learning spaces (pp. 575-582), Mathematics Education Research Group of Australasia, Adelaide, 2006. 
[12] A. Zohar. Teachers metacognitive knowledge and the instruction of higher order thinking, Teaching and Teacher Education, Vol.15, No.4, 413-429. 1999.

[13] B. Kaur. Difficulties with problem solving in mathematics, The Mathematics Educator, Vol.2, No.1, 93-1 12. 1997.

[14] B. Kramarski, Z. R. Mevarech, M. Arami. The effects of metacognitive instruction on solving mathematical authentic tasks, Educational Studies in Mathematics, Vol.49, No.2, 225-250. 2002

[15] C. E. Lance, M. M. Butts, L. C. Michels. The sources of four commonly reported cutoff criteria: what did they really say?, Organizational Research Methods, Vol.9, No.2, 202-220. 2006.

[16] D. K. Pugalee. A comparison of verbal and written descriptions of students' problem solving processes, Educational Studies in Mathematics, Vol.55, No. 1/3, 27-47. 2004.

[17] E. Kapa. A metacognitive support during the process of problem solving in a computerized environment, Educational Studies in Mathematics, Vol.47, 317-336. 2001.

[18] F. K. Lester, J. Garofalo, D. L. Kroll. The role of metacognition in mathematical problem solving: A study of two grade seven classes, Project Final Report, 1989.

[19] F. K. Lester, P.E. Kehle. From problem solving to modeling: The Evolution of thinking about reseach on complex mathematical activity. In R. A. Lesh \& H. M. Doerr (Eds.), Beyond constructivism: Models and modelling perspectives on mathematics problem solving, learning and teaching (pp. 501-517). Lawrance Erlbaum Associates Publishers, 2003.

[20] F. K. Lester. Mathematical problem solving research. In R. J. Shumway (Ed.), Research in mathematics education (pp. 286-323), VA: National Council of Teachers of Mathematics, Reston, 1980.

[21] F. K. Lester. Methodological considerations in research on mathematical problem-solving instruction. In E. A. Silver (Ed.), Teaching and learning mathematical problem solving: Multiple research perspectives (pp. 41-69), NJ: Lawrence Erlbaum Associates, Hillsdale, 1985.

[22] G. McKoon, R. Ratcliff. Inference during reading, Psychological Review, No.99, 440-466. 1992.

[23] G. Özsoy, A. Ataman. The effect of metacognitive strategy trainingon mathematical problem solving achievement, International Electronic Journal of Elementary Education, Vol.1, No.2, 68-83. 2009.

[24] G. Özsoy. An investigation of the relationship between metacognition and mathematics achievement, Asia Pacific Educ. Rev., No.12, 227-235. 2011.

[25] G. Polya. How to solve it: A new aspect of mathematical method, Princeton University Press, Princeton, 1957.

[26] G. Schraw, R. S. Dennison, Assessing metacognitive awareness, Contemporary Educational Psychology, No.19, 460-470. 1994

[27] H. Aydemir, Y. Kubaç. Investigation of the cognitive behavioral problem solving process, Turkish Studies, Vol.9, No.2, 203-219. 2014.

[28] H. J. Hartman. Metacognition in teaching and learning: An introduction, Instructional Science, Vol.26, No.1, 1-3. 1998.

[29] H. T. Y. Yong, L. N. K. Kiong. Metacognitive aspect of mathematics problem solving, MARA University of Technology Malaysia, Kuala Lumpur. 2006.

[30] İ. Bayazıt, Y. Aksoy. Matematiksel problemlerin öğrenim ve öğretimi. E. Bingölbali ve M. F. Özmantar (Eds.), İlköğretimde karşılaşılan matematiksel zorluklar ve çözüm önerileri (pp. 287-312). Pegem Akademi Yayınları, Ankara, 2009.

[31] J. Garofalo, F. K. Lester. Metacognition, cognitive monitoring, and mathematical performance, Journal for Research in Mathematics Education, Vol.16, No.3, 163-176. 1985.

[32] J. H. Flavell. Metacognitive aspects of problem solving. In L. Resnick (Ed.), The nature of intelligence (pp. 231-236), NJ: Erlbaum, Hillsdale, 1976.

[33] J. Wilson, D. Clarke. Towards the modelling of mathematical metacognition, Mathematics Education Research Journal, Vol.16, No.2, 25-48. 2004.

[34] J. Wilson. Methodological difficulties of assessing metacognition: A new approach, Annual Meeting of theAustralian Association for Research in Education, Australia, 2001. Online available from http://files.eric.ed.gov/fulltext/ED460143.pdf

[35] K. A. Ericsson, H. A. Simon. Verbal reports as data, Psychological Review, Vol.87, No.3, 215-251. 1980.

[36] M. L. Fernandez, N. Hadaway, J. W. Wilson. Problem solving: Managing it all. The Mathematics Teacher, Vol.87, No.3, 195-199. 1994.

[37] M. Nancarrow. Exploration of metacognition and non-routine problem based mathematics instruction on undergraduate student problem solving success, Unpublished Doctoral Dissertation, The Florida State University, College of Education, 2004.

[38] M. Q. Patton. Qualitative research \& evaluation methods (3th ed.), SAGE Publications, USA, 2002.

[39] M. V. D. Walt, K. Maree. Do mathematics learning facilitators implement metacognitive strategies?, South African Journal of Education, Vol.27, No.2, 223-241. 2007.

[40] M. V. J. Veenman, R. Kok, J. Kuilenburg. Intelligence and metacognitive skillfulness in secondary education. In F. Oser \& U. Baets (Eds.), 9th European Conference on Learning and Instruction, Abstract Volume (pp. 166), Aachen: Mainz, 2001 .

[41] N. L. Leech, A. J. Onwuegbuzie. A typology of mixed methods research designs, Qual Quant, Vol.43, No.2, 265-275. 2009

[42] National Council of Teachers of Mathematics [NCTM]. Assessment standards for school mathematics, VA: Author, Reston, 1995.

[43] National Council of Teachers of Mathematics [NCTM]. Curriculum and evaluation standards for school mathematics, VA: Author, Reston, 1989.

[44] National Council of Teachers of Mathematics [NCTM]. Principles and standards for school mathematics, VA: Author, Reston, 2000. 
[45] National Council of Teachers of Mathematics [NCTM]. Professional standards for teaching mathematics, VA: Author, Reston, 1991.

[46] P. W. Stewart, S. S. Cooper, L. R. Moulding. Metacognitive development in professional educators, The Researcher, Vol.21, No.1, 32-40. 2007.

[47] P. Wong. Metacognition in mathematical problem solving, Singapore Journal of Education, Vol.12, No.2, 48-58. 1992.

[48] R. Abu-Elwan. Reda. The development of mathematical problem posing skills for prospective middle school teachers, In A. Rogerson (Ed.), Proceedings of the International conference on Mathematical Education into 21st Century (pp. 1-8), Cairo, 1999.

[49] R. E. Mayer. Cognitive, metacognitive, and motivational aspects of problem solving, Instructional Science, No.26, 4963. 1998.

[50] R. Lesh. Conceptual analysis of problem-solving performance. In E. A. Silver (Ed.), Teaching and learning mathematical problem solving: Multiple research perspectives (pp. 309-329), NJ: Lawrence Erlbaum Associates Hillsdale, 1985.

[51] R. Zan. A metacognitive intervention in mathematics at university level, International Journal of Mathematical Education in Science and Technology, Vol.31, No.1, 143-150. 2000.

[52] S. Şengül, F. Y1ldız. The relation between the metacognitive behaviours demonstrated by students in their problem solving process with collaborative learning groups and their mathematical self- efficacy, International Journal of Social Science, Vol.6, No.1, 1295-1324. 2013.
[53] S. Şengül, Y. Katranc1. Meta-cognitive aspects of solving indefinite integral problems, Procedia - Social and Behavioral Sciences, No.197, 622 - 629. 2015.

[54] T. Tambychik, T. S. M. Meerah. Students' difficulties in mathematics problem-solving: What do they say?, Procedia Social and Behavioral Sciences, No.8, 142-151. 2010.

[55] Republic of Turkey Ministry of National Education. Secondary School Mathematics Teaching Program. Talim ve Terbiye Kurulu Başkanlığı, Ankara, 2013.

[56] W. Blum, M. Niss. Applied mathematical problem solving, modelling, applications, and links to other subjects-State, trends and issues in mathematics instruction, Educational Studies in Mathematics, Vol.22, No.1, 37-68. 1991.

[57] W. M. W. Jaafar, A. F. M. Ayub. Mathematics self-efficacy and meta-cognition among university students, Procedia Social and Behavioral Sciences, No.8, 519-524. 2010.

[58] Z. Ç. Küçük-Özcan. Teaching metacognitive strategies to 6th grade students, Unpublished master dissertation, Boğaziçi University, The Institute for Graduate Studies in Sciences and Engineering, 2000.

[59] Z. R. Mevarech, B. Kramarski. The effects of metacognitive training versus worked-out examples on students' mathematical reasoning, British Journal of Educational Psychology, No.73, 449-471. 2003.

[60] Z. R. Mevarech. Effects of metacognitive training embedded in cooperative settings on mathematical problem solving, The Journal of Educational Research, Vol.92, No.4, 195-205. 1999. 